\title{
Network Structure and Education Outcomes: Evidence from a field experiment in Bangladesh*
}

\author{
Youjin Hahn ${ }^{\dagger} \quad$ Asadul Islam ${ }^{\ddagger} \quad$ Eleonora Patacchini ${ }^{\S} \quad$ Yves Zenou $^{\Uparrow}$ \\ February 25, 2015
}

\begin{abstract}
We study the causal impact of network centrality on educational outcomes using field experiments in primary schools in Bangladesh. After obtaining information on friendship networks, we randomly allocate students into groups and give them individual and group assignments. We find that groups that perform best are those whose members have high Katz-Bonacich and key-player centralities. Leaders are mostly responsible for this effect, while bad apples have little influence. Own Katz-Bonacich centrality is associated with better individual performance only if it is above the average centrality of the group. Further experiments reveal that leadership, as measured by network centrality, mainly captures non-cognitive skills, especially patience and competitiveness.
\end{abstract}

JEL Classifications: A14, C93, D01, I20.

Keywords: Social networks, centrality measures, leaders, soft skills.

*We thank Quoc-Anh Do, Carlo L Del Bello and Ben Golub as well as the participants of the departmental seminar at Monash University for helpful comments and suggestions.

${ }^{\dagger}$ Monash University, Australia. E-mail: Youjin.Hahn@monash.edu.

$\ddagger$ Monash University, Australia. E-mail: Asadul.Islam@monash.edu.

$\S$ Cornell University, EIEF and CEPR, USA. E-mail: ep454@cornell.edu.

『Stockholm University and IFN, Sweden, and CEPR. E-mail: yves.zenou@ne.su.se. 


\section{Introduction}

We investigate the importance of group members' popularity in shaping individual and group performance in the context of education outcomes. We measure student popularity using the individual position in her network of social contacts. This study is the first to look at the importance of network centrality in shaping performance in a group production process using randomly allocated groups. ${ }^{1}$

We conduct a large scale field experiment in rural primary schools in Bangladesh where we randomly allocate students into groups. In June 2013, we collect students' friendship network and conducted a separate household survey in 80 schools for fourth-graders to obtain information on demographic characteristics, education, family background and friendship. We also collected behavioral characteristics for pupils in a subset of schools by conducting standard games commonly used in experimental economics. From a network perspective, the most interesting aspect of this dataset is the friendship information, which is based upon actual friends nominations. Indeed, pupils were asked to identify their best friends from a school roster (up to 10 nominations). Therefore, we have the whole network of interactions of students in each school. We end up with 3,406 students distributed over 80 networks. Then, in July 2013, we design our experiment by randomly allocating students into groups of four in each classroom. We balance the group characteristics so that they have on average the same ability level and the same observable characteristics. We then ask students to perform different tests on general knowledge and math, both in the very short run (i.e. when the groups are just formed) and in the longer run (a week after the groups have been formed). Some of the tests were performed collectively by the group while some others were performed individually.

Our analysis mainly focuses on two questions. First, we examine whether and how the centrality of members of randomly assigned groups affect the group and the individual test scores. Second, having found evidence of the existence of some effects, we then investigate their underlying mechanism. Economists have long speculated about the importance of the individual position in a network of social contacts for decision making processes, but few studies have been able to explain the underlying mechanisms. This study is among the first to get inside the black box of network centrality measures. Our conjecture is that network centrality measures, especially Katz-Bonacich and key-player centralities, capture some of the non-cognitive or soft skills of a student. As a result, groups with high key-player and

\footnotetext{
${ }^{1}$ The economics of networks is a growing field in economics. For recent overviews, see Ioannides (2012), Jackson (2008, 2011, 2014), Jackson et al. (2015), Jackson and Zenou (2015) and Topa and Zenou (2015).
} 
Katz-Bonacich centrality are the groups that include popular and social students who can promote study activities and learning practices amongst group members, enforce decisions and stimulate discussions. To investigate if, indeed, these centrality measures (and others) capture the soft skills of the students, we perform additional experiments. We make our students play some games that capture personal traits such as risk-taking behavior, patience and competitiveness.

The elaboration of the data collected from our experiments shows the following evidence. Firstly, our results show that the Katz-Bonacich and key-player average centrality of the group have a significant and positive impact on the group performance in the short run. This is an interesting result because, in the short run, the students did not have time to interact with each other and thus this is a pure "centrality" effect. Interestingly, we find that these two centrality measures also matter for the longer-run group outcomes, when longer run means here one week after the groups were randomly formed.

When we look at individual outcomes, we show that only own centrality matters. In other words, the centrality of other students in my group does not affect my individual performance, even though I have interacted with them during a week solving the group assignment before I perform my own test. Interestingly, we show that own Katz-Bonacich centrality and own degree centrality (which simply looks at the number of friends each student has) are the best predictors of individual performance.

We further investigate whether and to what extent there are effects stemming from the relative (rather than absolute) position of each group member in terms of centrality. For that, we investigate the impact of deviations of own centrality compared to the average centrality of the group, of the leader or star in the group (i.e. the student with the highest centrality in the group) and of the weakest link or bad apple in the group (i.e. the student with the lowest centrality in the group) on the group's and the individual's outcomes both in the short and in the longer run.

First, we find that there is a positive effect of own centrality on individual performance only when the individual centrality is above the average centrality of the group. Second, we find that leaders play an important role in group outcomes in the short and longer run. In other words, it is often the student with the highest centrality in the group that affects the collective performance of the group. Third, this last result is not true for bad apples or weakest links. Indeed, the student with the lowest centrality in the group has nearly no impact on the group performance. Finally, even if my own centrality is the main determinant of my individual outcome, the presence of a leader in my group reinforces the former effect.

To wrap up, groups that perform best are those with high average Katz-Bonacich and 
key-player centralities with a high dispersion. Leaders are mostly responsible for this effect while bad apples have little impact.

When looking at the data collected from our additional experiments on students' soft skills, we find that there are strong correlations between time preference or patience and competitive behaviors of our students and their key-player centrality as well as their KatzBonacich centralities. We also test whether each centrality captures the cognitive skills of the student as measured by their ability (captured by the test score at the individual math test taken before the experiment). We find that, for all centrality measures, there is no significant correlation between centrality measures and ability, which seems to indicate that centrality measures do capture non-cognitive skills (or soft skills) rather than cognitive skills. These results suggest that the personal traits of students that are conductive of high-quality collective and individual works are patience and competitiveness. The results do not provide any evidence which suggest that a student's risk-taking behavior could help students work efficiently both in groups and individually.

The rest of the paper unfolds as follows. In the next section, we relate our paper to the literature and highlight our contribution. In Section 3, we give some background of the educational system in Bangladesh. Section 4 is devoted to the description of our dataset and the experimental design. In Section 5, we detail the regressions that we estimate and our results. In Section 6, we investigate the mechanisms behind our results by studying the extent to which centrality measures capture cognitive or non-congnitive skills. Finally, Section 7 concludes.

\section{Related literature}

Our paper is related to different literatures.

\section{Peer effects in education}

An important literature on peer effects and education looks at the causal impact of peers on educational outcomes using field experiments (see e.g. Angrist and Lavy, 1999; Sacerdote, 2001; Zimmerman, 2003). ${ }^{2}$ For example, Sacerdote (2001) and Carrell et al. (2009) study specific contexts in which first-year roommates (or hallmates or squadron mates in the case of military academies) are randomly assigned by the housing office. This creates exogenous variation in one's peer group, which is then used to ask how much peers matter, which peers matter, and for what outcomes. They find strong peer effects in education. A recent paper by Carrell et al. (2013) examine squadron mates in the case of military academies. They

\footnotetext{
${ }^{2}$ For an overview of this literature, see Sacerdote (2011, 2014).
} 
manipulate the groups by putting together low-ability and high-ability incoming cadets at the US Air Force Academy. They show that performance for the lower-ability students fell relative to lower-ability students in the randomly assigned control group.

Compared to this literature, we study network topology effects rather than peer effects. While adopting the same methodology that ensures a random allocation of the peers, we consider the impact of network characteristics (such as centrality measures) on educational outcomes.

\section{Non-cognitive versus cognitive skills}

Another important literature in education is the one about the distinction between cognitive skills (grades) and non-cognitive skills (soft skills). It is well documented that cognitive ability (or skill) is a strong predictor of education success. Economists, psychologists, and sociologists are now actively examining determinants of social and economic success beyond those captured by cognitive ability (see e.g. Borghans et al., 2008). For example, a recent analysis of the Perry Preschool Program shows that personal traits other than those measured by IQ and achievement tests causally determine life outcomes (see, in particular, Heckman et al., 2010; 2011). Traits such as perseverance and preferences related to an interest in learning might lead people to attain more total years of schooling. Indeed some evidence suggests that this might be the case. For example, Heckman et al. (2006) show that better adolescent personality traits — as measured by locus of control and self-esteem - increases the probability of graduating from, and stopping at, high school for males at the lowest quantiles of the personality distribution. Cunha et al. (2010) use a dynamic factor model to investigate the development of both cognitive skills and personality traits during childhood, allowing for endogenous investment in skills and dynamic complementarities. They find that adolescent personality - as measured by a variety of behavior inventories - accounts for $12 \%$ of the variation in educational attainment, whereas adolescent cognitive ability accounts for $16 \%$ of the variation (see Almlund et al., 2011, for a review).

To summarize, this literature shows that soft skills (such as motivation, tenacity, trustworthiness, conscientiousness, honesty, and perseverance) predict success in life, that they causally produce that success, and that programs that enhance soft skills have an important place in an effective portfolio of public policies (Heckman and Kautz, 2012).

Soft skills, however, are difficult to measure. While the measures of soft skills used in these papers are self-reported, we adopt an indirect approach. Our analysis contributes to this literature by showing that measures of student's popularity in the school are correlated with student's soft or non-cognitive skills. Our results suggest that, indeed, centrality and thus soft skills (mostly patience and competitiveness) do affect the performance of the students 
and that they should be taken into account in education policies.

\section{Centrality in networks}

Bavelas (1948) and Leavitt (1951) were among the first to use centrality to explain differential performance of communication networks and network members on a host of variables including time to problem solution, number of errors, perception of leadership, efficiency, and job satisfaction. Following their work, many researchers have investigated the importance of the centrality of agents on different outcomes. Indeed, various studies from different disciplines have shown that centrality is important in explaining employment opportunities (Granovetter, 1974), peer effects in crime (Haynie, 2001), power in organizations (Brass, 1984), the success of open-source projects (Grewal et al., 2006) as well as workers' performance (Mehra et al., 2001). On the other hand, economists are familiar with the difficulty of ascertaining cause and effect in such complex constructs and have remained dubious about the identification of the effects. The main challenge is the endogeneity of the network. ${ }^{3}$

A possible way out is to use controlled experiments. In the field of networks, this has been implemented by either $(i)$ fully controlling the network of relationships in the laboratory (Choi et al., 2005; Kearns et al., 2009) or (ii) assigning subjects in the field positions in a network through which they must communicate (Centola, 2010, 2011; Goeree et al., 2010; Babcock and Hartman, 2010; Cai et al., 2015). In the latter papers, the network is still endogenous and not randomized. What is randomized is the intervention. For example, in Babcock and Hartman (2010), the network is self-reported and thus not random but subjects (students at U.C. Santa Barbara) have different fractions of their friends who are being randomly treated (free access to exercise at the university gym).

Here we use a field experiment where agents embedded in a friendship network are randomly allocated to groups. We believe this is one of the first papers that uses such a strategy in the context of networks to evaluate the causal impact of centrality on outcomes.

\footnotetext{
${ }^{3}$ Some economists have addressed the question about which measure of centrality is appropriate to predict which behavior. For example, in cases in which there are strong complementarities in behaviors such as in crime, education or R\&D collaborations, Katz-Bonacich and key-player centrality (defined in Appendix 5) have proven useful in describing the activity of each agent (Ballester et al., 2006; Calvó-Armengol et al., 2009; Liu et al., 2012, 2015; Lindquist and Zenou, 2014; König et al., 2014; Zenou, 2015). In contrast, when studying the diffusion of information, Katz-Bonacich centrality is not always a strong predictor of which people are the most influential seeds for the process, and other centrality measures outperform it. Indeed, in investigating microfinance diffusion in 43 different villages in India, Banerjee et al. (2013) find that the eigenvector centrality of the first contacted individuals (i.e. the set of original injection points in a village) are the only significant predictors of the eventual diffusion. In all these papers, the endogeneity of the network is tackled using a structural approach.
} 


\section{Leadership and social networks}

There is a literature in management and psychology that increasingly recognizes the importance of social processes and relational linkages in shaping leadership. In addition to resources that stem from human capital, organizational capacities can also be derived from social relationships - the so-called social capital. In economics, while studies on the effects of social networks on a variety of outcomes are pervasive, the intersection between leadership and social networks has received limited attention. Some recent papers look at some related issues. Tao and Lee (2014) define peer pressure using some extreme order statistics (i.e. maximum value of the peer performance) rather than using the average level of activity. Using data from German 9th-graders, Tatsi (2014) find that bad apples are more important than classroom stars in affecting educational outcomes. Mastrobuoni and Patacchini (2012) document that network centrality, especially eigenvalue centrality, is an important predictor of leadership in the US mafia organization. In line with this latter strand of research, in this paper, we use student popularity, as measured by network centrality, to define leaders (i.e. those having the highest value of centrality in a friendship network). This paper is the first to assess the importance of the presence of a leader in a group in shaping group performance, as well as the performance of each group member.

\section{Peer effects in productivity}

Finally, although we look at the education performance of fourth-grader kids, the design and results of our experiment may be helpful to understand the effects of team composition on individual and group performance. In contrast with the pervasive use of teams in the organization of work, few empirical studies have systematically examined the impact of teams on output. Consequently, relatively little is known about the determinants of individual and group performance when individuals interacts in groups. There is only a limited literature on peer effects in productivity. Guryan et al. (2009) consider performance of professional golfing pairs, where their parings are randomly assigned and the pairings are competitors not teammates. Bandiera et al. (2009) investigate how social connections between workers and managers affect the productivities of fruit pickers in the United Kingdom. Their measure of social connectedness is based on similarities of worker/manager characteristics (e.g., nationality) and there are multiple managers whose worker assignments change daily. They also conduct a field experiment where they exogenously vary manager compensation schemes, allowing them to perform a more nuanced analysis of the effect of worker/manager connectedness on worker productivity. Mas and Moretti (2009) consider peer effects in the performance of supermarket cashiers, where pairing of peers is assumed to be exogenous, but do not specifically employ teams or networks in their analysis. Hamilton et al. (2003) 
analyze the effect of team composition on clothing manufacturing, providing support for the view that teams utilize collaborative skills, which are less valuable in individual production. Moreover, they consider and explicitly model individual self-selection into teams. Horrace et al. (2015) consider the estimation of productivity spillovers in a network production function where the allocation of workers into teams is strategic and done by a manager.

This study is the first to investigate the impact of team composition in terms of individual popularity (i.e. centrality) on individual and group performance.

To sum-up, our contributions to these literatures are: (i) We address the endogeneity issue of the network by randomly allocate students to groups; (ii) Within a clean identification framework, we show that the average Katz-Bonacich and key-player centrality of the group as well as that of the leader positively affect the individual and the group outcome both in the short and long run; (iii) We show that these centrality measures capture the soft skills of the students, mostly their degree of patience and competitiveness.

\section{Background and context}

\subsection{Education in Bangladesh}

As mentioned, we conduct field experiments in rural primary schools in Bangladesh. The education system in Bangladesh is broadly divided into three major levels: primary, secondary and tertiary education. Primary education is free and compulsory for children aged six to ten years (grades 1-5). The secondary education has three sub-stages: junior secondary (grade 6-8), secondary (grade 9 and 10), and higher secondary (grade 11 and 12). The main forms of provision include government primary schools, registered non-government primary schools (private schools), ibtidayee madrasahs (religious schools) and NGO schools. The majority of private schools are registered as non-government primary (RNGP) schools. The RNGP schools follow the same curriculum as government schools.

Bangladesh has achieved tremendous progress over recent decades in reducing gender disparity. From 1990 to 2009, the gender parity index (ratio of girls to boys) increased from 0.83 to 1.01 in primary schools and from 0.51 to 1.07 in secondary schools. According to Bangladesh Bureau of Educational Information and Statistics (2012), the gross enrolment at primary schools has fallen from 116 per cent in 2000 to 105.8 per cent in 2012 . Over the same period, net enrolment increased from 81.8 per cent to 96.4 per cent . However, school dropout rates and grade repetition rates are high. In 2010, nearly 50 percent of primary school students drop out before completing grade five, while about 12.5 per cent students repeat 
grade at the primary level. The quality of education remains the greatest concern, as there is still a large gap between expectations and achievements. According to the Department of Primary Education of Bangladesh, around 70 percent of children who complete primary education are unable to read, write or count properly. As in many other developing countries, these are attributed to high teacher and student absenteeism, low classroom teaching time, and high student-teacher ratio. At primary level teacher-student ratio is 1 to 50 .

The government also introduced the food for education (FFE) Program in 1993 to support poor children in completing primary schooling. The primary education stipend project replaced the FFE Program in 2002 and has been providing cash transfers to households of children in poor areas on the condition that these children remain enrolled at primary school and maintain a minimum attendance level. In addition, a variety of policies such as the elimination of official school fees and free textbooks have been put in place to encourage school enrolment (Mahmud et al 2013). In mid-1990s, the government also introduced a stipend program in secondary schools in rural area for girl children. These programs have been associated with a substantial rise in female education in both primary and secondary level and have effectively reversed the gender gap in secondary education (Begum et al. 2013).

\subsection{Teaching-learning contexts and assessment practices}

The National Curriculum and Textbook Board prepares the curriculum from primary to higher secondary level. In the case of general primary education, a single curriculum caters for all students across the country. The existing embedded practice of using textbooks in Bangladesh suggests that textbooks could be considered as the "de-facto curriculum" as teachers tend to rely on this single textbook. Students are assessed by the items taken from the textbook, and tests often demand answers to be copied from the textbook. School education is exam-driven because the success of teachers and schools is measured by students' results in the exams (Holbrook, 2005). As the school exams mostly demand memorization and recall of the content from the textbooks (Holbrook, 2005), teachers often encourage students to rote learning (Tapan, 2010). They mostly work on preparing students for the exams.

At present, there are three public examinations in the first ten years of schooling: (a) at the end of primary school (grade five), (b) at the end of junior secondary level (grade eight), and (c) at the end of secondary level (grade ten). Students' results in these examinations are important as they are used to determine students' promotion from one grade to another grade as well as marks in these exams are used to determine students' future study aspirations. 
Class size in schools is typically very large. This large class size challenges teachers in ensuring student engagement. Teachers often resort to lecturing that hinders the opportunity of student engagement. Sometimes teachers try to engage students in active learning by involving them in large group activities. But there is hardly any grouping where teachers teach separately. Because of the resource constraints, single teachers teach the entire class of students. Occasionally, student groups are used for extra-curricular project activities. There is no common grouping mechanism exists in Bangladesh. Teachers sometimes make groups on an ad-hoc basis based on academic performance such as good performing students are encouraged to learn from each other. There is no particular seating arrangement for students' within the classroom. In most cases, good performing students sit in the front rows to get teachers' attention, whereas the low performing students, often termed as "the backbenchers", sit in the back rows. Teachers hardly take special care of the backbenchers to improve their learning.

\section{Experimental design and data description}

Let us now explain our experimental design in the context of Bangladesh schools. The experimental design involved grouping based on students' friendship network within-classroom among grade-four students in rural primary schools. The experiments were conducted in 80 schools in two districts (Khulna and Satkhira) in Bangladesh (there are a total 64 districts in Bangladesh). See Figure 1 to see where these regions are located in Bangladesh. There are more than 800 primary schools in these two districts.

\section{[Insert Figure 1 here]}

The experiments were conducted under the direct supervision of the researchers. The enumerators and the field workers who actually run the experiments in schools were given a week-long training by the researchers. The final experiments were conducted after pretesting and piloting in a few different set of schools to make sure the students understand grouping and that the test and the designs were appropriate at their level. The project received enormous supports from the schools teachers and administration.

Let us now describe the timing of our experiments (see Figure 2). In June 2013 (referred to as period $t-1$ ), we conducted a network survey of all the students in the 80 schools by asking them to name up to 10 closest friends (the network), starting from the most closest to the least closest friends. See Appendix 1 for a description of the network questionnaire.

[Insert Figure 2 here] 
Because the ranking of friends is important, we consider a directed network with weights. In the language of graph theory (Wasserman and Faust, 1994; Jackson, 2008), in a directed graph, a link has two distinct ends: a head (the end with an arrow) and a tail. Each end is counted separately. The sum of head endpoints counts toward the indegree and the sum of tail endpoints counts toward the outdegree. Because we mainly used our networks to construct centrality measures, we will consider an indegree directed network so that the more popular students will be the ones who are nominated the most by other students. Formally, we denote a link from $i$ to $j$ as $g_{i j} \in[0,1]$ if $j$ has nominated $i$ as his/her friend, and $g_{i j}=0$, otherwise. The indegree of student $i$, denoted by $d_{i}$, is the number of nominations student $i$ receives from other students, that is $d_{i}=\sum_{j} g_{i j}$. For each network, we can then define an adjacency matrix $\mathbf{G}=\left[g_{i j}\right]$, which is asymmetric because the network is directed. For the weights $g_{i j} \in[0,1]$, each non-zero entry $g_{i j}$ of the adjacency matrix $\mathbf{G}$ is defined as:

$$
g_{i j}=1-\frac{(\vartheta-1)}{d_{i}}
$$

where $\vartheta$ denotes the order of nomination given by individual $j$ to friend $i$ in his/her nomination list. Finally, we will consider connected networks, which means that the underlying undirected graph is connected (i.e., ignoring the directions of edges). This implies that we will have roughly as many networks as classes or schools (since there is only one grade-four class per school in Bangladesh).

In order to illustrate how we determine a directed weighted network in the data, consider an hypothetical class of four students with the following nominations: $(i)$ individual 1 nominates individual 2 first, then 3 and then 4 ; individual 2 nominates individual 1 first and then 4; individual 3 nominates individual 2 first and then individual 4; individual 4 nominates nobody. This directed network can be represented as follows: 


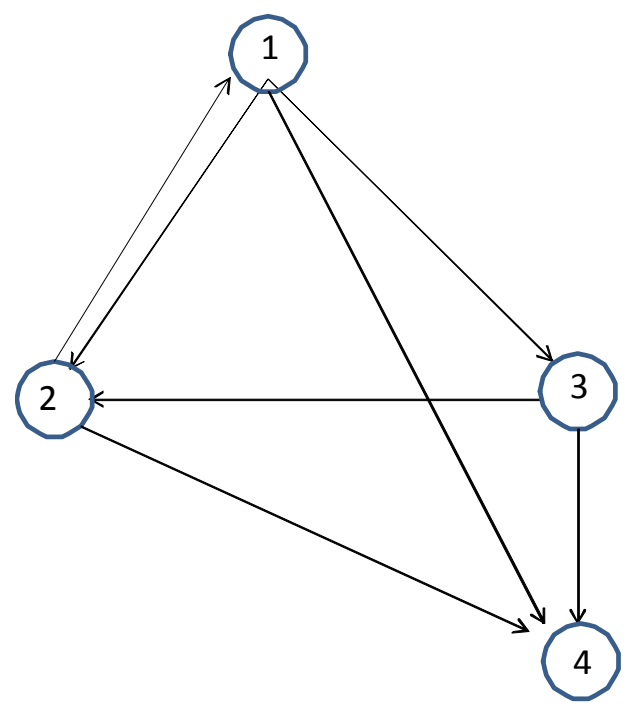

We can then calculate the weights given to each student according to (1) by computing the weighted directed adjacency matrix as follows:

$$
\mathbf{G}=\left(\begin{array}{cccc}
0 & 1 & 0 & 0 \\
1 & 0 & 1 & 0 \\
2 / 3 & 0 & 0 & 0 \\
1 / 3 & 1 / 2 & 1 / 2 & 0
\end{array}\right)
$$

It is easy to interpret this matrix G. Take column 1 . It gives which person individual 1 has nominated and in which order. We can see that individual 1 has nominated first individual 2 (weight 1 ), then individual 3 (weight $2 / 3$ ) and then individual 4 (weight $1 / 3$ ). The same interpretation can be given for each column. By doing so, we will be able to measure the weighted popularity of each individual. For example, individual 4 has nominated nobody but has been nominated by everyone but never as the first person. If, as a measure of popularity, we just count the number of weighted links (indegree centrality), then, even if 4 has the highest number of links, his/her indegree is lower than that of individual 2 who has only two links since $2>1 / 3+1 / 2+1 / 2$.

In June 2013, we also conducted a separate household survey, which contained questions on parent education, parent age, parent occupation, and other household characteristics. We finally conducted an individual pre-experiment math test (IPEMT) for each student to measure their ability, which will help us balance groups by average ability. See Appendix 1 for a detailed description of the IPEMT.

In July 2013 (referred to as period $t$ ), one month after, at the beginning of the week, the experiment was conducted and groups of four were formed in each school. We considered 
pure random groups, where students were randomly allocated to a group of 4 within a school. Newly formed groups were asked to solve a group general knowledge test (GGKT) (see Appendix 2, for a description of this test), which was performed collectively by each group of 4 . What is important is that this test was taken instantly following the formation

of the group. Students were not informed about the test or its content before the test was administered.

Then, after the group general knowledge test was performed, each group were given a group math test (GMT) to be completed collectively and handed over by the end of the week (referred to as period $t+1$ ). See Appendix 3, for a description of this test. Finally, at the end of the week (i.e. at $t+1$ ), after each group had handed over their GMT, each individual had to take an individual post-experiment math test (IPOMT) (described in Appendix 4). In addition to the IPOMT, students were asked to complete a short questionnaire that seeks information regarding their group/individual effort to solve the assignment problems. The questions included (1) the number of times students met as a team (extensive margin); (2) how many hours the group met as a team (intensive margin); (3) how many hours a student spent in total doing the group math test; (4) how many hours a student spent in total studying on his/her own. Prizes were then given to the most successful students (see below).

\subsection{Random-grouping of students}

Let us be more explicit about the random grouping of students (our experiment). Fourthgrader students in participating schools were randomly grouped in order to observe how peers and different network centrality measures affect student outcomes. In 80 schools, we randomly allocate students in groups. Each group contains 4 students and any student has equal chance of being in one or the other group since groups are generated by a randomnumber generator. To implement random grouping that has relatively similar mean across groups, we rank students by their individual pre-experiment math test (IPEMT) (taken at period $t-1)$. We then randomly select a student from each quartile to form a group of size four. We order the student list within each class based on this characteristic (IPEMT). For all 80 schools, the ANOVA F-test fails to reject at the $5 \%$ level that we have similar test score (IPEMT) means over the groups. This means that groups are well-balanced in terms of ability. We also balanced the groups based on other characteristics such as parents' education and household income.

Observe that we are making group based on IPEMT and household characteristics. We are not using any information on friendship network to identify groups. We will use the friendship information ex post to understand what kind of network centrality matters in 
influencing the group outcome.

Figure 3 plots the composition of friends in each random group of four for each individual in the 80 schools where the maximum number of friends each student has is 3 . As expected, for these random groups, most individuals end up in a group where very few students are their friends (in more than $50 \%$ of the cases, a student has no friend at all).

$$
\text { [Insert Figure } 3 \text { here] }
$$

Figure 4 describes the same pattern but for the total number of links within a group, which, for a group of 4 , is at most 12 . The distribution shows a clear random pattern of friendship links since few friendship links exist. This gives us confidence that the distribution of friendships within each group is random and that we can use the variation of friendship links and thus of centrality measures in our empirical exercises.

$$
\text { [Insert Figure } 4 \text { here] }
$$

\subsection{Outcome measures, group assignment, and incentives}

Let us describe in more details the different outcomes that we are considering. The collective grade at the group general knowledge test (GGKT) is a short-term outcome as it was administered right after the students were assigned to their respective groups. As the students did not have a chance of spending much time together, the initial network structure is likely to stay the same and this allows us to examine the impact of pure network effects on outcomes. On the contrary, the individual grade at the individual post-experiment math test (IPOMT) is our measure of long-term outcome, as students were given a full week to interact with each other and then take the test.

\section{Group general knowledge test (short-term group outcome measure)}

Once the groups were randomly formed (July 2013, period $t$ ), students participated in a group general knowledge test (GGKT) on the first day of the grouping. The GGKT consisted of 20 multiple choices items that aimed to explore students' knowledge regarding national and international affairs, geographical aspects, current affairs, and sports (see Appendix 2). 20 minutes were allocated to respond to this test. Students discussed to elicit the best answer they could deliver given 20 minutes time frame. It was an exam-like situation and the students were not informed about the content of the test. The best performing group got a prize as announced before the test was taken. Every member of best performing group got the same prize. The multiple prizes were given if two or more groups received the same marks. 


\section{Group math test (long-term group outcome measure)}

After participating in the group general knowledge test, students were provided at period $t$ with a group math test (GMT) that was due in a week time (period $t+1)$. Students completed the test with their respective group members. The test consisted in 10 questions or problems (Appendix 3). While the questions reflected the content in Grade 4 mathematics textbook, they were not directly taken from the textbook. We considered some international mathematics testing (e.g., NAPLAN) prepared for students of their age. Following NAPLAN, we presented the mathematical problems to students as related to their real life contexts. The problems reflected the knowledge, skills, understandings and capacities that are essential for every child to learn mathematics at grade level four. The tests were developed in consultation with retired school teachers and local educational experts. Students were told that, they would take an individual test after one week, and that the completion of the assignment would help them to do well in the test. They were also informed that prizes would be given based on the group performance (overall group members' individual test scores), so that they have incentives to help each other during a week of interaction period.

Individual post-experiment math test (long-term individual outcome measure)

After one week (period $t+1$ ), they were asked to sit for an individual post-experiment math test (IPOMT), which was developed on the basis of the group math test (GMT) they completed. None of the test item was repeated (or copied) from the GMT, but completion of the GMT items helped students answer to the IPOMT. There were 10 problems in the test and 1.5 hours were allocated to respond to these problems. All students answered to the test individually. Similar to the other tests problems, the test problems were also presented as related to students' real life contexts. Observe that all tests (IPEMT, GGKT, GMT and IPOMT) are standardized across the 80 schools so that the average value of the test score is zero.

\section{Prizes and incentives}

Students were given prizes based on their performance in the different math tests. While students responded to the math test individually, the prizes were determined by their group's performance. Two prizes were given in each class: one prize for the group with the highest average score in the IPOMT (best performing group), and another prize for the group with highest improvement from their group average baseline math test. This was done to ensure that all the students were incentivized to work together and help each other during the week to complete the assignments, and also to individually do well on the day of the individual 
test. Every member of best performing group and highest improvement received the same prize.

For the group general knowledge test, the prize was a pencil box scale (ruler) for each student of the best performing group, while for IPOMT they were given an instrument box (geometry box) or diary and scale. These prizes were set in consultation with teachers and students to make sure they are incentive compatible. The cost of prize for each student in the best group(s) was approximately US $\$ 1$. If two or more groups received the same highest score, all of them got the prizes. In our research, all participant children received gifts (e.g., a pencil/pen) and certificates for their participation. In addition, some children received more of the same gifts depending on their performance as described above. In Bangladesh, it is common that students receive prizes and/or public recognition from their schools/teachers for their performances in classroom or in exam results. Thus, it was not unusual that some students receiving more than others.

\subsection{Data Description}

Table 1 presents some information about our data. We see that there are roughly as many female as male students. The majority of the households in this region of rural Bangladesh lack access to electricity and only $28 \%$ of the sample students have access to electricity at home. Parental education is measured as the maximum of mother's years of education and father's years of education. Parental educational attainment on average is 5 years, and illiteracy rate is high; about 40 percent of the parents are either illiterate or can sign only.

Table 1 also contains descriptive statistics about individual and group performance in the different tasks. As one can see, there is a notable dispersion in terms of performance in our sample. In order to be able to compare them, all our test scores have mean zero and a standard deviation of 1 .

\section{[Insert Table 1 here]}

Table 2a collects descriptive statistics on different measures of individual centrality that are used in the literature to capture the position of each individual in the friendship network (Wasserman and Faust, 1994; Jackson, 2008). There are many centrality measures and we will focus on the most prominent ones, which are formally defined Appendix 5. Let us give some intuitive meaning of each centrality and their implications. ${ }^{4}$ Degree centrality simply measures the number of links each agent has. As a result, it captures a direct measure of

\footnotetext{
${ }^{4}$ Each centrality measure can be defined both for undirected and directed networks (Waserman and Faust, 1994).
} 
popularity. Betweenness centrality of a given agent is equal to the number of shortest paths between all pairs of agents that pass through the given agent. In other words, an agent is central, if she lies on several shortest paths among other pairs of agents. Betweenness centrality thus captures the importance as an intermediary. Such central agents have control over the flow of information in the network, which is related to the notion of structural holes developed by Burt (1992), who postulates that social capital is created by a network in which people can broker connections between otherwise disconnected segments of the network. Closeness centrality is a measure of how close an agent is to all other agents in the network. The most central agents can quickly interact with all others because they are close to all others. This measure of centrality captures how easily an individual reaches others, i.e., how informed a given individual is in the context of information flows. Eigenvector centrality is a measure of the influence of an agent in a network. It assigns relative scores to all agents in the network based on the concept that connections to high-scoring agents contribute more to the score of the agent in question than equal connections to low-scoring agents. It thus captures indirect reach so that being well-connected to well-connected others makes you more central. For example, Google's PageRank is a variant of the eigenvector centrality measure. The Katz-Bonacich centrality (due to Katz, 1953, and Bonacich, 1987) takes all possible paths in a network (not only the shortest ones) but puts a lower weight to nodes that are further away from the agent. As a result, Katz-Bonacich centrality captures the influence of friends and of their friends. If there are strong network externalities, it can be shown that Katz-Bonacich centrality becomes proportional to the eigenvector centrality (see Wasserman and Faust, 1994, Chap. 5.2). Finally, the key-player centrality (Ballester et al., 2006, 2010; Ballester and Zenou, 2014; Zenou, 2015) proposes a normative view of centrality. The key player is the agent who, once removed, generates the highest reduction is total activity in the network. In some sense, the key-player centrality (or intercentrality) shows how crucial an agent is in terms of the stability of the network. The main implication of this centrality is that the planner should target the key players in a network.

Table $2 \mathrm{a}$ shows that there are very large variations in individual centrality measures. It appears that the centrality measures that are between zero and one, i.e. betweenness, closeness and degree centrality, have quite small average values with large dispersion around this mean value. The maximum betweenness centrality equal to 0.365 means that one student has $36.5 \%$ of shortest paths that go through him/her.

\section{[Insert Table $2 a$ here]}

Panel B of Table 2a collects summary statistics of network characteristics. One can see that the average size of our networks is 51 , which corresponds to the average size of 
the classroom. Indeed, in our sample every student is usually path-connected to any other student in the same classroom. Because there is one class per grade in each school, in our sample all fourth grades are in the same network and there is one network in each school. In fact, we see that the density of the network is quite low (20\%), which is due to the relatively large size of networks. However, both the diameter and the average path length are quite small (4.7 and 1.7, respectively), indicating small world properties of these networks.

Table $2 \mathrm{~b}$ reports summary statistics of the average, maximum and minimum centrality across groups. They show notable variations. The variation is only limited for the minimum value of centrality when it is measured using betweenness, eigenvector and degree centrality. Figure 5 shows the empirical distribution of the group-average centrality measure. It confirms a notable dispersion, even though the distribution is skewed to the left for most of the centrality measures.

\section{[Insert Table $2 b$ and Figure 5 here]}

\section{$5 \quad$ Empirical analysis}

The aim of our empirical analysis is to investigate the extent to which group and individual performances are affected by the centralities of the members of the team. Our measure of group outcomes are the general knowledge test (GGKT) and the group math test (GMT), where the score in a group of four is at the group level and thus the same for all four students. Our measure of individual outcome is the individual post-experiment math test (IPOMT) where the grade is individual specific. Our analysis proceed as follows. In Section 5.1, we consider the impact of the average centrality of the group and of the individual centrality on group and individual outcomes whereas, in Section 5.2, we look at asymmetric effects, i.e. the deviations from the average centrality of the group. In Section 5.3, we consider the extent to which the distribution of centralities within a group affects outcomes. In particular, we uncover the role of leaders (stars) and weakest links (bad apples) on outcomes.

\subsection{Average centrality and own centrality}

We estimate regressions of the form:

$$
y_{i r s}=\beta_{0}+\beta_{1} \bar{C}_{i r s}+\beta_{2} A_{i r s}+\beta_{3} X_{i r s}+\eta_{s}+\epsilon_{i r s}
$$

where $y_{\text {irs }}$ is the test score of individual $i$ belonging to group $r$ in school $s$ in either the GGKT, the GMT or the IPOMT, $\bar{C}_{i r s}$ is the average centrality measure of the group $r$ 
to which $i$ belongs to (we look separately at each of the six centrality measures defined in Appendix 5), including individual $i, A_{\text {irs }}$ is the ability (i.e. his/her test score in the IPEMT) of individual $i$ belonging to group $r$ in school $s, X_{\text {irs }}$ corresponds to the observable characteristics of individual $i$ (which include gender, parent's education, access to electricity, etc.; see Table 1), $\eta_{s}$ is the school fixed effects and $\epsilon_{i r s}$ is an error term. Moreover, for group outcomes (GGKT and GMT), we use group-level regressions, controlling for average ability $\left(\bar{A}_{\text {irs }}\right)$ and average characteristics $\left(\bar{X}_{\text {irs }}\right)$ of individuals belonging to group $r$. Standard errors are clustered at the school level.

Observe that, as mentioned in the data description, in Bangladesh class size is large and there is only one fourth-grader class for each school. As a result, school fixed effects would capture all unobserved school specific factors. For example, if teacher quality differ between schools, then this is captured by school fixed effects- all fourth graders in a school will face the same teacher. Observe also that school fixed effects are here equivalent to network fixed effects since there is one (path-connected) network in each school. ${ }^{5,6}$

For the IPOMT, which is taken individually by student $i$, we also disentangle the effect of individual $i$ 's centrality from that of the group centrality, using the model

$$
y_{i r s}=\beta_{0}+\beta_{1} \bar{C}_{-i r s}+\beta_{2} C_{i r s}+\beta_{3} A_{i r s}+\beta_{4} X_{i r s}+\eta_{s}+\epsilon_{i r s}
$$

where

$$
\bar{C}_{-i r s}=\frac{1}{3} \sum_{j \neq i} C_{j r s}
$$

denotes the average centrality of group $r$ to which $i$ belongs to, which excludes individual $i$. $\bar{C}_{i r s}$, which is the average centrality of the whole group of 4 people can be written as

$$
\bar{C}_{i r s}=\frac{\bar{C}_{-i r s}+C_{i r s}}{4}
$$

where $C_{i r s}$ is the centrality of individual $i$.

Our identification strategy can be summarized as follows. We have a setting where groups are exogenously formed. In our estimation, we always control for school fixed effects and control for group characteristics, and we cluster standard errors at the school level. The impact of the group centrality on outcomes should be causal since we only use the variation between groups that is exogenous.

\footnotetext{
${ }^{5}$ The use of network fixed effects to controll for unobserved factors common to all network members in the analysis of peer effects is a traditional practice in the network literature (see e.g. Bramoullé et al., 2009).

${ }^{6}$ Finally, observe that we do not have the reflection problem (Manski, 1993) here because $\bar{C}_{\text {irs }}$, our key explanatory variable, is different from our endogenous variable $y_{i r s}$ and that $\bar{C}_{i r s}$ is only common to the four students who are in the same group.
} 


\section{Results}

The empirical results are displayed in Table 3 where columns (1), (2) and (3) correspond to the test of equation (2) while column (4) corresponds to the test of equation (3). Observe that, even if all centralities are reported in the same column in Table 3, we test the impact of each average centrality using separate regressions.

First, we see that the average betweenness centrality of the group has no impact on the GGKT, the GMT and the IPOMT. We also see that own betweenness centrality has no impact on own IPOMT. These results indicate that the betweenness centrality of students have no impact on educational outcomes in our schools in Bangladesh, a result also obtained by Calvó-Armengol et al. (2009) for students in the United States. The remaining centrality measures instead show a positive and significant impact. This is an important result, which indicates that, being randomly exposed to a group whose members have high centrality (as measured by key-player, or intercentrality, Katz-Bonacich, closeness, eigenvector or degree centrality) increases the group performance both in the short run (when the group is just formed for the GGKT) and in the longer run (a week after the group is formed for the GMT). Interestingly, this result is also true for the IPOMT (column (3)), which is taken a week after the groups were formed at period $t+1$ in July 2013 and which is performed individually. In order to better understand this last result, in column (4), we estimate equation (3), which distinguishes between own centrality $C_{i r s}$ ("Own centrality") and group centrality $\bar{C}_{-i r s}$ ("Avg. centrality"). We see clearly that what is driving the results of column (3) is own centrality since the effect of $\bar{C}_{-i r s}$ on the IPOMT of student $i$ becomes non-significant when we decompose the two effects. In other words, the centrality of other students in my group does not appear to be relevant in shaping my individual performance.

\section{[Insert Table 3 here]}

The next interesting question is what is the centrality measure with the highest predictive power. To answer this question, we test the explanatory power of each centrality measure against each other. In Table 4, we report the correlations between our six measures of centralities. We see that the Katz-Bonacich and the key-player centrality show an almost perfect correlation (correlation of 0.954). The correlations between the other centrality measures range between 0.2 and 0.8. Observe also that Katz-Bonacich and key-player centralities are the only centrality measures that are microfounded through a model of social interactions (see Appendix 5). While their microfoundation is somehow different, both of them are a function of the same parameter and consider the entire network topology in shaping individual centrality in a recursive manner (Ballester et al., 2006, 2010). The extremely high 
correlation of these two measures in our case implies that we cannot really distinguish their relative importance. However, our analysis can shed some light on the relative importance of measures stemming from a behavioral foundation (Katz-Bonacich and key-player centralities) and those that merely depend on network topology (degree, eigenvector, closeness and betweenness centralities).

\section{[Insert Table 4 here]}

Since we have five out of six centrality measures that are statistically significant in Table 3 , we focus only on them and perform 10 different regressions for the GGKT and the GMT (group outcomes) where we include two centrality measures in each regression. In Table 5, we only report the results for the measures that show significant results most frequently.

We see that, the Katz-Bonacich and the key-player centrality (or intercentrality) of the group have a significant and positive impact on the short run test (GGKT). This is an interesting result because, for the GGKT, the students did not have time to interact with each other and thus this is pure centrality effect. Similarly, for the long run group test (GMT), where students had more time to interact and spend time with each other (they had one week to perform this collective test), we find that the Katz-Bonacich centrality and the key-player centrality are the measures which have the most impact on outcomes.

\section{[Insert Table 5 here]}

Let us now focus on individual outcomes, i.e. the IPOMT. In Table 3 column (4), we have seen that it is only my own centrality that has an impact on the IPOMT. To investigate which own centrality matters, we regress the five centralities against each other (10 regressions) while controlling for the average centrality of the three students in my group, i.e. $\bar{C}_{-i r s}$. In Table 6 , we only report the results for the centrality measure that appears significant most frequently. We find that the Katz-Bonacich centrality and degree centrality are the best predictors of the IPOMT. We will attempt to understand what mechanisms are behind our results in Section 6.

[Insert Table 6 here]

\section{$5.2 \quad$ Asymmetric effects}

The effects of the individual centrality on individual performance when individuals interact in groups may depend on whether the individual centrality is below or above the average 
centrality of the group. For that, we estimate the following model:

$y_{i r s}=\beta_{0}+\beta_{1}\left|C_{i r s}-\bar{C}_{-i r s}\right|+\beta_{2} \mathbf{1}_{\left\{C_{i r s}>\bar{C}_{-i r s}\right\}}+\beta_{3}\left|C_{i r s}-\bar{C}_{-i r s}\right| \times \mathbf{1}_{\left\{C_{i r s}>\bar{C}_{-i r s}\right\}}+\beta_{4} A_{i r s}+\beta_{5} X_{i r s}+\eta_{s}+\epsilon_{i r s}$

where the variables $A_{\text {irs }}, X_{\text {irs }}, \eta_{s}$ and $\epsilon_{\text {irs }}$ are the same as in (2) and where $y_{\text {irs }}$ is the test score of individual $i$ belonging to group $r$ in school $s$ for IPOMT. There are three new variables. First, $\left|C_{i r s}-\bar{C}_{-i r s}\right|$ measures the deviation of individual $i$ 's centrality from the average centrality of the group. Second, the indicator variable $\mathbf{1}_{\left\{C_{i r s}>\bar{C}_{-i r s}\right\}}$ is equal to one if individual $i$ 's centrality is above the average centrality of the group and zero otherwise. Finally, we also study cross effects by adding $\left|C_{i r s}-\bar{C}_{-i r s}\right| \times \mathbf{1}_{\left\{C_{i r s}>\bar{C}_{-i r s}\right\}}$. If $\beta_{3}$ is positive, this would mean that, conditional on having a centrality above the average centrality of the group, it is beneficial for student $i$ in terms of IPOMT to deviating from the average centrality of the group. To be more precise, by differentiating (4), we obtain:

$$
\left.\frac{\partial y_{i r s}}{\partial\left|C_{i r s}-\bar{C}_{-i r s}\right|}\right|_{C_{i r s}>\bar{C}_{-i r s}}=\beta_{1}+\beta_{3}
$$

which measures the effect of $\left|C_{i r s}-\bar{C}_{-i r s}\right|$ on $y_{\text {irs }}$ conditional on having a centrality above the average centrality of the group. We also have:

$$
\left.\frac{\partial y_{i r s}}{\partial\left|C_{i r s}-\bar{C}_{-i r s}\right|}\right|_{C_{i r s}<\bar{C}_{-i r s}}=\beta_{1}
$$

Table 7 displays the results of the estimation of equation (4) for each of the six different centralities. First, since betweenness centrality did not affect the IPOMT (Table 3), it still does not show any impact. Second, we see that for the other centralities $\beta_{1}$ is not significant, whereas the interaction effect captured by $\beta_{3}$ is nearly always significant. This means that, conditional on having a centrality above the average centrality of the group, the higher is student $i$ 's centrality, the higher is his/her test score in the IPOMT. Consider, for example, the Katz-Bonacich centrality. Then we see that $\beta_{1}+\beta_{3}=-0.004+0.075=0.071>0$, and the cross effect is indeed positive. If we now consider the intercentrality (key player), then both $\beta_{2}$ and $\beta_{3}$ are significant and positive. For $\beta_{2}$, this means that having a centrality that is higher than that of the average of the group, i.e. $1_{\left\{C_{i r s}>\bar{C}_{-i r s}\right\}}$ has a positive impact on the individual test score (IPOMT).

[Insert Table 7 here] 


\subsection{Leadership versus weakest link}

Let us now study the extent to which "extreme" centralities within a group affects outcomes. Indeed, even if two groups have the same average centrality, it is possible that, in one group, there is a person with a very high centrality and another person with a very low centrality while, in the other group, all members have the same centrality. For that, we now study the role of leaders (stars) and weakest links (bad apples) in shaping outcomes.

To investigate the role of a leader in a group, we estimate the following equation:

$$
y_{i r s}=\beta_{0}+\beta_{1} \max _{j \in r} C_{j r s}+\beta_{2} A_{i r s}+\beta_{3} A_{\max _{j \in r} C_{j r s}}+\beta_{4} X_{i r s}+\eta_{s}+\epsilon_{i r s}
$$

where the variables $y_{\text {irs }}, A_{\text {irs }}, X_{\text {irs }}, \eta_{s}$ and $\epsilon_{\text {irs }}$ are the same as in (2). There are now two new variables. First, to test the leadership effect, we introduce $\max _{j \in r} C_{j r s}$, which is the student with the highest centrality within the group, including individual $i$. We control for the ability of student $i$ by having $A_{\text {irs }}$. We also control for the ability of the student with the highest centrality in the group by adding $A_{\max _{j \in r} C_{j r s}}$ in the regression. As in (2), $y_{i r s}$ is the test score of individual $i$ belonging to group $r$ in school $s$ in either the GGKT, the GMT or the IPOMT. The idea here is to test the role of leadership in groups. Furthermore, we also investigate which centrality measure matters the most for leadership.

To study the weakest-link effect, we estimate equation (5) where we replace $\max _{j \in r} C_{j r s}$ by $\min _{j \in r} C_{j r s}$ and $A_{\max _{j \in r} C_{j r s}}$ by $A_{\min _{j \in r} C_{j r s}}$.

\section{Results: Group outcomes}

Table 8 displays the results. Panel A contains the evidence on the effects of the leaders. As above, even if all centralities are reported in the same column, we test the impact of each average centrality on outcomes separately.

Interestingly, the results are similar to that of Table 3 when we look at the impact of the average group centrality on group outcomes (GGKT and GMT; columns (1) and (2)) and individual outcome (IPOMT; column (3)). Indeed, we find that the impact of a leader, including myself, is positive and significant for five centrality measures (Katz-Bonacich, keyplayer, closeness, eigenvector and degree centrality). This means that having a leader in a group, i.e. a student with a high centrality, increases the group performance both in the short run (when the group is just formed for the GGKT) and in the longer run (a week after the group is formed for the GMT). In terms of magnitude, the effects of maximum centrality and of average centrality are comparable. For example, one can see that, in terms of standard deviations, one standard deviation increase in the average Katz-Bonacich centrality (from Table 3 ) translates into about $12 \%$ of a standard deviations of the GGKT. This is about the same effect that is obtained for the maximum Katz-Bonacich centrality (from Table 8). 
Panel B contains the evidence on the effects of the least central individuals, i.e. the weakest links (or bad apples) in a group. Interestingly, contrary to the leadership effects where all centrality measures had a significant impact on both the GGKT and the GMT (Table 8, Panel A), we see that the weakest link has nearly no impact on the GGKT and on the GMT. In other words, if the weakest link is measured as the person (including myself) with the lowest centrality in my group, then this person has nearly no impact on the group's short-run (GGKT) and long-run outcome (GMT).

\section{[Insert Table 8 here]}

In Table 9, we investigate further the effect of leadership on group outcomes. We have seen in Table 8 that most centralities of the leader had a positive impact on the GGKT and the GMT of the group. Interestingly, in Table 9, when we regress one centrality against the other, we see that again the Katz-Bonacich centrality is the main determinant of the test score for the short-run test (GGKT) and key-player centrality and Katz-Bonacich centrality for the longer-run test (GMT). In other words, leaders with a high Katz-Bonacich and keyplayer centrality are the ones that positively affect the outcomes of the group.

\section{[Insert Table 9 here]}

\section{Results: Individual outcomes}

Let us now attempt to better understand the role of the leader (maximum centrality) and the role of own centrality on the individual outcome, IPOMT. For that, we estimate the the following equation:

$y_{i r s}=\beta_{0}+\beta_{1} \max _{j \in r, j \neq i} C_{j r s}+\beta_{2} C_{i r s}+\beta_{3}\left\{\max _{j \in r, j \neq i} C_{j r s}\right\} \times C_{i r s}+\beta_{4} A_{i r s}+\beta_{5} A_{\max _{j \in r} C_{j r s}}+\beta_{6} X_{i r s}+\eta_{s}+\epsilon_{i r s}$

In Table 10, column (1), we only report the effect of the leader (i.e. $\max _{j \in r, j \neq i} C_{j r s}$ ) on own IPOMT. In column (2), we look at both the effect of the leader and of own centrality $\left(C_{i r s}\right)$ on own IPOMT. Finally, in column (3) we display the results when we estimate the whole equation (6). We see that the significant effect of the leader on own IPOMT (column (1)) disappears as soon as we introduce own centrality in the regression (column (2)). Interestingly, in column (3), we report $\beta_{1}, \beta_{2}$ and $\beta_{3}$ on the first, second and third row of each panel (i.e. for each centrality measure). It appears that $\beta_{3}$, the cross effect, is significant and positive for the key-player and Katz-Bonacich centrality, which are the centralities for which own centrality had a significant impact on IPOMT. This means that, 
for these centralities, the leader reinforces the impact of one's centrality on the IPOMT.

$$
\text { [Insert Table } 10 \text { here] }
$$

Let us now consider the effect of the weakest link (lowest centrality) on own IPOMT. Table 11 has exactly the same structure as Table 10. For example, column (3) reports the results of the estimation of (6) where we replace $\max _{j \in r, j \neq i} C_{j r s}$ by $\min _{j \in r, j \neq i} C_{j r s}$, $\left\{\max _{j \in r, j \neq i} C_{j r s}\right\} \times C_{i r s}$ by $\left\{\min _{j \in r, j \neq i} C_{j r s}\right\} \times C_{i r s}$ and $A_{\max _{j \in r} C_{j r s}}$ by $A_{\min _{j \in r} C_{j r s}}$. We see, again, that, as soon as own centrality is introduced in the regression (column (2)), the weakest link in my group has no impact on my own IPOMT. However, differently from the results on the leader, we see that the cross effect is never significant. In other words, the weakest link in my group has no additional effect on the positive impact of one's centrality on IPOMT.

\section{[Insert Table 11 here]}

Our results can be summarized as follows. For group outcomes, the group performance in the short run (GGKT) is positively affected by the average centrality of the team members, as summarized by the average Katz-Bonacich and/or key-player centrality. In the longer run (GMT), key-player centrality has the greatest impact. Leaders are important. In the short run, leaders defined using the Katz-Bonacich centrality are the most influential, whereas, in the long run, leaders defined using either Katz-Bonacich centrality or key-player centrality are also the most important persons in a group. Bad apples in a working group has no impact on the group outcomes. For individual outcomes (IPOMT), when working in groups, the most important predictor of individual performance (IPOMT) remains the individual centrality, especially the Katz-Bonacich, the key-player and the degree centrality. However, this is true only if the individual centrality is higher than the average of the group. Finally, the individual performance is also affected by the presence of a leader, as defined by the person with the highest key-player centrality or degree centrality in the group since the latter reinforces the positive effect of one's centrality on one's IPOMT. The bad apple in a working group has no impact on individual performance.

\section{Inspecting the mechanisms}

In this Section, we investigate the mechanisms behind our results. We conjecture that network centrality measures, especially the Katz-Bonacich and the key player centrality, which indicate popularity and sociability of students, capture some non-cognitive or soft skills of the students. 
In order to investigate our conjecture, we have performed additional experiments. We have randomly selected 16 schools out of the 80 schools. In these 16 schools all students of grade four $(\mathrm{N}=512)$ were asked to play experimental games to test their risk-taking behavior, patience and competitiveness. Mean baseline math test score of these 16 schools is 6.896 (out of 15) which is very similar to the mean test score of 6.898 for the same test among the students in 80 schools. In Appendix 6, we describe in details each of these three games. ${ }^{7}$

Let us summarize what each game captures. In the risk taking game, we measure the degree of riskiness of each student. There are five pencils in the jar with only one pencil having a red mark on the bottom. The student can take as many pencils as they choose to take out from the jar, as long as the pencil with red mark is not included in the selected pencils. Thus, the more a student decides to take pencils out of the jar (out a total of five), the more he/she enjoys risk. In the time preference game, we see how patient are students. This game asks students to make some choices about candies and they must decide between having a plate of candies tomorrow or after two days. We observe whether the student choose to wait (i.e. get candies after two days rather than tomorrow) as a measure of patience. Finally, in the competition game, we evaluate how competitive the students are. Students are asked to sum a series of four two-digit numbers. Students can choose one of two options. If the student chooses option 1 , the student will get 1 candy for each correct answer. If option 2 was chosen, the student will be randomly paired with another person in the class to compete. The students who chose option 2 will be given two candies for each correct answer if they win, and nothing if they loose compared to a random partner in the class. Our outcome for competitiveness is whether the student chooses to compete, that is, takes option 2.

These experimental measures of risk, time preference and competitiveness are closely related to soft skills or non-cognitive skills in the literature on economics of education (Koch, et al., 2015). Previous literature found that risk attitudes play a significant role in education and labor market outcomes (Castillo et al., 2010; Liu, 2013). For instance, Belzil and Leonardi $(2007,2013)$ find that students with high risk aversion invest less in higher education investment. Competition or confidence is also claimed to have a strong impact on labor market outcomes. Gneezy et al. (2003) and Niederle and Vesterlund (2007) study a gender gap in competitiveness as a potential explanation for a gender gap in wage.

\footnotetext{
${ }^{7}$ The games in the experiments we conducted are standard games used by economists to elicit behaviors among children or in similar settings (e.g., Andersen et al. 2013; Bettinger and Slonim 2007; Cameron et al. 2013; Gneezy et al., 2003, 2009; Samak, 2013).
} 
In order to investigate whether centrality measures capture the non-cognitive skills, we run a series of regressions where the variable to be explained is each of the six centralities and the main explanatory variables are game outcomes and ability of students. The results are displayed in Table 12. First, in column (1), we regress each centrality on the ability of each student, captured by the test score at the individual math test taken before the experiment, i.e. the IPEMT. It should be clear that ability, as measured by the test score at the IPEMT, is a measure of cognitive skill. Second, in columns (2) and (3), controlling for ability (or IPEMT), we look at the impact of the different non-cognitive skills (risk taking, time preference and competitiveness) on centrality measures with (column (3)) and without other controls (column (2)).

\section{[Insert Table 12 here]}

First, looking at all columns (1), we see that, for all the centrality measures, there is no significant correlation between centrality measures and ability (or IPEMT). This seems to indicate that centrality measures do not capture cognitive skills.

Second, when we look at the other columns, we see that there are strong correlations between time preference or patience and competitive behaviors of our students and their intercentrality measure (or key-player centrality) and their Katz-Bonacich centralities. This is suggestive evidence that, indeed, these two centrality measures capture some of the personal traits (or soft skills) of the students, namely their degree of patience and competitiveness. If we look at the other results, we also see that competitiveness is strongly related with the four other centrality measures. In other words, the more students are competitive, the higher is their centrality. Finally, it seems that the eigenvector centrality and the closeness centrality are correlated with the risk-taking behavior of students. Overall, these results suggest that centrality measures could provide important information about students' non-cognitive ability.

Let us now try to understand our previous results in the light of the games played in the experiments, We have found that, for group outcomes, in the short run, both the Katz-Bonacich and key-player centrality of the group and of the leader have a positive and significant impact on the GGKT. For the longer run outcome, the key-player of the group and the Katz-Bonacich and key-player centrality of the leader have a positive and significant impact on the GMT. This would mean that students who are both very patient and very competitive have a big impact on group outcomes. In other words, the non-cognitive skills or personal traits of students that are conductive of high-quality collective work are patience and competitiveness. This is also true for individual outcomes such as the IPOMT. Risk- 
taking behavior does not seem to be a personal trait that helps students work efficiently both in groups and individually.

\section{Conclusion}

In this paper, we show that the position in a network of social contacts as measured by network centrality, especially the Katz-Bonacich and the key-player centrality, is a key determinant of educational success. We also show that these measures capture some personal traits, namely their patience and competitiveness. Our results thus support the literature on non-cognitive skills, which shows that soft skills predict success in life and that programs that enhance soft skills have an important place in an effective portfolio of public policies (Heckman and Kautz, 2012). One implication of our analysis is that educational policies should target groups formed on the basis of these soft skills and not necessarily on the students' cognitive skills (ability). Also, our results on the influence of leaders in working groups suggest that individuals who are perceived as leaders because of their social network position can be used to specifically target and diffuse opinions as well as accelerate the diffusion of innovations. We leave this promising area of research for further studies.

\section{References}

[1] Almlund, M., Duckworth, A.L., J. Heckman and T. Kautz (2011), "Personality Psychology and Economics," In: Handbook of the Economics of Education, Vol. 4, Amsterdam: Elservier, pp. 1-181.

[2] Andersen, S., Ertac, S., Gneezy, U., List, J.A. and S. Maximiano (2013), "Gender, competitiveness and socialization at a young age: Evidence from a matrilineal and a patriarchal society," Review of Economics and Statistics 95, 1438-1443.

[3] Akerlof, G.A. (1997), "Social distance and social decisions," Econometrica 65, 10051027.

[4] Akerlof, G.A. (1997), "Social distance and social decisions," Econometrica 65, 10051027.

[5] Angrist, J. and V. Lavy (1999), "Using Maimonides' rules to estimate the effect of class size on scholastic achievement," Quarterly Journal of Economics 114, 533-575. 
[6] Babcock, P.S. and J.L. Hartman (2010), "Networks and workouts: Treatment size and status specific peer effects in a randomized field experiment," NBER Working Paper No. 16581.

[7] Ballester, C., Calvó-Armengol, A. and Y. Zenou (2006), "Who's who in networks. Wanted: the key player," Econometrica 74, 1403-1417.

[8] Ballester, C., Calvó-Armengol, A. and Y. Zenou (2010), "Delinquent networks," Journal of the European Economic Association 8, 34-61.

[9] Ballester, C. and Y. Zenou (2014), "Key player policies when contextual effects matter," Journal of Mathematical Sociology 38, 233-248.

[10] Bandiera, O., Barankay, I. and I. Rasul (2009), "Social connections and incentives in the workplace: Evidence from personnel data," Econometrica 77, 1047-1094.

[11] Banerjee, A., Chandrasekhar, A.G., Duflo, E. and M.O. Jackson (2013), "Diffusion of microfinance," Science 341 (6144).

[12] Bangladesh Bureau of Educational Information and Statistics [BANBEIS] (2012), "Basic education statistics 2011," http://www.banbeis.gov.bd/webnew.

[13] Bavelas, A. (1948), "A mathematical model for group structures," Human Organization 7, 16-30.

[14] Begum, L., A. Islam and R. Smyth (2013), "Girls' education, stipend programs and their effects on the education of younger siblings," Monash Economics Working Papers 17-13, Monash University, Department of Economics.

[15] Belzil, C. and M. Leonardi (2007), "Can risk aversion explain schooling attainments? Evidence from Italy," Labour Economics 14 (6), 957-970.

[16] Belzil, C. and M. Leonardi (2013), "Risk aversion and schooling decisions," Annals of Economics and Statistics, 35-70

[17] Bettinger, E. and R. Slonim (2007), "Patience among children," Journal of Public Economics 91, 343-363.

[18] Bifulco, R., Fletcher, J.M. and S.L. Ross (2011), "The effect of classmate characteristics on post-secondary outcomes: Evidence from the Add Health," American Economic Journal: Economic Policy 3, 25-53. 
[19] Bonacich P. (1987), "Power and centrality: A family of measures," American Journal of Sociology 92, 1170-1182.

[20] Borghans, L.,Duckworth,A.L.,Heckman,J.J., and B, ter Weel (2008), "The economics and psychology of personality traits," Journal of Human Resources 43, 972-1059.

[21] Brass, D. J. (1984), "Being in the right place: A structural analysis of individual influence in an organization," Administrative Science Quarterly 29, 518-539.

[22] Bramoullé, Y., Djebbari, H. and B. Fortin (2009), "Identification of peer effects through social networks," Journal of Econometrics 150, 41-55.

[23] Burt, R.S. (1992), Structural Holes: The Social Structure of Competition. Harvard: Harvard University Press.

[24] Cai, J., de Janvry, A. and E. Sadoulet (2015), "Social networks and the decision to insure," American Economic Journal: Applied Economics, forthcoming.

[25] Calvó-Armengol, A., E. Patacchini, and Y. Zenou (2009), "Peer effects and social networks in education," Review of Economic Studies 76, 1239-1267.

[26] Calvó-Armengol, A. and Y. Zenou (2004), "Social networks and crime decisions. The role of social structure in facilitating delinquent behavior," International Economic Review 45, 939-958.

[27] Cameron, L.A., Erkal, N., Gangadharan, L. and X. Meng (2013), "Little emperors: Behavioral impacts of China's one-child policy," Science 339 (6122), 953-957.

[28] Carrell, S.E., Fullerton, R.L. and J.E. West (2009), "Does your cohort matter? Estimating peer effects in college achievement," Journal of Labor Economics 27, 439-464.

[29] Carrell, S.E., Sacerdote B.I. and J.E. West (2013), "From natural variation to optimal policy? The importance of endogenous peer group formation," Econometrica 81, 855882.

[30] Castillo, M., Petrie,R. and M. Torero (2010), "On the preferences of principals and agents," Economic Inquiry 48, 266-273.

[31] Centola, D. (2010), "The spread of behavior in an online social network experiment," Science 329, 1194-1197. 
[32] Centola, D. (2011), "An experimental study of homophily in the adoption of health behavior," Science 334, 1269-1272.

[33] Choi, S., Gale, D., and S. Kariv (2012), "Social learning in networks: A quantal response equilibrium analysis of experimental data," Review of Economic Design 16,93-118.

[34] Cunha, F., Heckman,J.J., and S.M. Schennach (2010), "Estimating the technology of cognitive and noncognitive skill formation," Econometrica 78, 883-931.

[35] Currarini, S., Jackson, M.O., and P. Pin (2009), "An economic model of friendship: Homophily, minorities, and segregation," Econometrica 77, 1003-1045.

[36] Currarini, S., Jackson, M.O., and P. Pin (2010), "Identifying the roles of race-based choice and chance in high school friendship network formation," Proceedings of the National Academy of Sciences of the USA 107, 4857-4861.

[37] Dequiedt, V. and Y. Zenou (2014), "Local and consistent centrality measures in networks", CEPR Discussion Paper No. 10031.

[38] Fortin, B. and V. Boucher (2015), "Some challenges in the empirics of the effects of networks," In: Y. Bramoullé, B.W. Rogers and A. Galeotti (Eds.), Oxford Handbook on the Economics of Networks, Oxford: Oxford University Press, forthcoming.

[39] Gneezy, U, Niederle, M. and A. Rustichini (2003), "Performance in competitive environments: Gender differences," Quarterly Journal of Economics 143, 1049-1074.

[40] Gneezy, U, Leonard, K.L. and J.A. List (2009), "Gender differences in competition: Evidence from a matrilineal and a patriarchal society," Econometrica 77, 1637-1664.

[41] Goeree, J.K., M.A. McConnell, T. Mitchell, T. Tromp, and L. Yariv (2010), "The 1/d Law of Giving," American Economic Journal: Micro-Economics 2, 183-203.

[42] Granovetter, M.S. (1974), Getting a Job: A Study in Contacts and Careers, Cambridge, MA: Harvard University Press.

[43] Grewal, R., Lilien, G. L. and G. Mallapragada (2006), "Location, location, location: How network embeddedness affects project success in open source systems," Management Science 52, 1043-1056. 
[44] Guryan, J., Kroft, K. and M.J. Notowidigdo (2009), "Peer effects in the workplace: Evidence from random groupings in professional golf tournaments," American Economic Journal: Applied Economics 1, 34-68.

[45] Hamilton, B.H., Nickerson, J.A. and H. Owan (2003), "Team incentives and worker heterogeneity: An empirical analysis of the impact of teams on productivity and participation," Journal of Political Economy 111, 465-497.

[46] Haynie, D. (2001), "Delinquent peers revisited: Does network structure matter?" American Journal of Sociology 106, 1013-1057.

[47] Heckman, J.J. and T. Kautz (2012), "Hard evidence on soft skills," Labour Economics 19, 451-464.

[48] Heckman, J.J.,Malofeeva, L., Pinto, R. and P.A. Savelyev (2011), "Understanding the mechanisms through which an influential early childhood program boosted adult outcomes," Unpublished manuscript, Department of Economics, University of Chicago.

[49] Heckman, J.J., Moon, S.H., Pinto, R., Savelyev, P.A. and A. Yavitz (2010), "The rate of return to the High Scope Perry Preschool Program," Journal of Public Economics 94, 114-128.

[50] Heckman, J.J., Stixrud, J. and S. Urzua (2006), "The effects of cognitive and noncognitive abilities on labor-market outcomes and social behavior," Journal of Labor Economics 24,411-482.

[51] Holbrook, J. (2005), "Report on organizing the ROSE survey in Bangladesh," http://www.uv.uio.no/ils/english/research/projects/rose/partners/bangladesh/reportbgd.pdf.

[52] Horrace, W., Liu, X. and E. Patacchini (2015), "Endogenous network production function with selectivity," Journal of Econometrics, forthcoming.

[53] Ioannides, Y.M. (2012), From Neighborhoods to Nations: The Economics of Social Interactions, Princeton: Princeton University Press.

[54] Jackson M.O. (2008), Social and Economic Networks, Princeton, NJ: Princeton University Press. 
[55] Jackson, M.O. (2011), "An overview of social networks and economic applications," In: J. Benhabib, A. Bisin and M.O. Jackson (Eds.), Handbook of Social Economics Volume 1A, Amsterdam: Elsevier Science, pp. 511-579.

[56] Jackson, M.O. (2014), "Networks in the understanding of economic behaviors," Journal of Economic Perspectives 28, 3-22.

[57] Jackson, M.O., Rogers, B.W. and Y. Zenou (2015), "The economic consequences of social network structure", CEPR Discussion Paper 10406.

[58] Jackson, M.O. and Y. Zenou (2015), "Games on networks", In: P. Young and S. Zamir (Eds.), Handbook of Game Theory, Vol. 4, Amsterdam: Elsevier Publisher, pp. 91-157.

[59] Katz, L. (1953), "A new status index derived from sociometric analysis," Psychometrika 18, 39-43.

[60] Kearns, M.J., Judd, S., Tan, J. and J. Wortman (2009), "Behavioral experiments on biased voting in networks," Proceedings of the National Academy of Sciences of the USA $106,1347-1352$.

[61] Koch, A., Nafziger, J. and H. Skyt Nielsen (2015), "Behavioral economics of education," Journal of Economic Behavior and Organization, forthcoming.

[62] König, M.D., Liu, X. and Y. Zenou (2014), "R\&D networks: Theory, empirics and policy implications," CEPR Discussion Paper No. 9872.

[63] Leavitt, H.J. (1951), "Some effects of certain communication patterns on group performance," Journal of Abnormal and Social Psychology 46, 38-50.

[64] Lindquist, M.J. and Y. Zenou (2014), "Key players in co-offending networks," CEPR Discussion Paper No. 9889.

[65] Liu, E.M. (2013), "Time to change what to sow: Risk preferences and technology adoption decisions of cotton farmers in China," Review of Economics and Statistics 95, 1386-1403.

[66] Liu, X., Patacchini, E. and Y. Zenou (2014), "Endogenous peer effects: Local aggregate or local average?" Journal of Economic Behavior and Organization 103, 39-59.

[67] Liu, X., Patacchini, E., Zenou, Y. and L-F. Lee (2012), "Criminal networks: Who is the key player?" CEPR Discussion Paper No. 8772. 
[68] Liu, X., Patacchini, E., Zenou, Y. and L-F. Lee (2015), "Who is the key player? A network analysis of juvenile delinquency," Unpublished manuscript, Stockholm University.

[69] Mahmud, W, Asadullah,N, and Savoia, A. (2013), "Bangladesh's achievements in social development indicators. Explaining the puzzle," Economic and Political Weekly 48, no 44.

[70] Manski, C.F. (1993), "Identification of endogenous effects: The reflection problem," Review of Economic Studies 60, 531-542.

[71] Mas, A. and E. Moretti (2009), "Peers at work," American Economic Review 99, 112145.

[72] Mehra, A., Kilduff, M. And D. J. Brass (2001), "The social networks of high and low self-monitors: Implications for workplace performance," Administrative Science Quarterly 46, 121-146.

[73] Niederle, M., and L. Vesterlund (2007), "Do women shy away from competition? Do men compete too much?," Quarterly Journal of Economics 122, 1067-1101.

[74] Mastrobuoni, G. and E. Patacchini (2012), "Organized crime networks: An application of network analysis techniques to the American mafia," Review of Network Economics 11, Article No. 10.

[75] Patacchini, E. and Y. Zenou (2012), "Juvenile delinquency and conformism," Journal of Law, Economics, and Organization 28, 1-31.

[76] Sacerdote, B. (2001), "Peer effects with random assignment: Results from Dartmouth roomates," Quarterly Journal of Economics 116, 681-704.

[77] Sacerdote, B. (2011), "Peer effects in education: How might they work, how big are they and how much do we know thus far?", In: E.A. Hanushek, S. Machin and L. Woessmann (Eds.), Handbook of Economics of Education, Vol. 3, Amsterdam: Elevier Science, pp. 249-277.

[78] Sacerdote, B. (2014), "Experimental and quasi-experimental analysis of peer effects: Two steps forward," Annual Review of Economics 6, 253-272.

[79] Samak, A.C. (2013), "Is there a gender gap in preschoolers' competitiveness? An experiment in the U.S.," Journal of Economic Behavior $\&$ Organization 92, 22-31. 
[80] Tao, J. and L.-F. Lee (2014), "A social interaction model with an extreme order statistic," Econometrics Journal 17, 197-240.

[81] Tapan, M.S.M. (2010), "Science education in Bangladesh," In: Y.-J. Lee (Ed.), World of Science Education: Science Education Research in Asia, Rotterdam: Sense, pp. 17-34.

[82] Tatsi, E. (2014), "Endogenous social interactions: Which peers matter?" Unpublished manuscript, Goethe University, Frankfurt.

[83] Topa, G. and Y. Zenou (2015), "Neighborhood and network effects", In: G. Duranton, V. Henderson and W. Strange (Eds.), Handbook of Regional and Urban Economics, Vol. 5, Amsterdam: Elsevier Publisher, forthcoming.

[84] Wasserman, S. and K. Faust (1994), Social Network Analysis. Methods and Applications, Cambridge: Cambridge University Press.

[85] Zenou, Y. (2015), "Key players," In: Y. Bramoullé, B.W. Rogers and A. Galeotti (Eds.), Oxford Handbook on the Economics of Networks, Oxford: Oxford University Press, forthcoming.

[86] Zimmerman, D. (2003), "Peer effects in academic outcomes: Evidence from a natural experiment," Review of Economics and Statistics 9-23. 


\section{Appendix 1:}

Baseline Questionnaire for Students and Individual Pre-Experiment Math Test (IPEMT) 
This questionnaire seeks information regarding your friendship network. Please answer the questions carefully. You are asked to write about your favourite friends. You will write about your best friend first, and so on. You can write up to ten names.

Your Name:

Your Father's Name:
Class:

Name of your School:

\begin{tabular}{|c|c|c|c|c|c|c|c|c|c|c|}
\hline $\begin{array}{l}\text { Sl } \\
\text { No. }\end{array}$ & $\begin{array}{l}\text { Name of your } \\
\text { favourite friend } \\
\text { (please write the } \\
\text { name of your best } \\
\text { friend first) }\end{array}$ & $\begin{array}{l}\text { What } \\
\text { is the } \\
\text { class } \\
\text { Roll } \\
\text { No. of } \\
\text { your } \\
\text { friend? }\end{array}$ & $\begin{array}{l}\text { Is your } \\
\text { friend a } \\
\text { boy or } \\
\text { a girl? } \\
1=\text { Boy } \\
2=\text { Girl }\end{array}$ & $\begin{array}{l}\text { Which class } \\
\text { does your } \\
\text { friend study } \\
\text { in? } \\
3=\text { Class Three } \\
4=\text { Class Four } \\
5=\text { Class Five } \\
6=\text { Class Six }\end{array}$ & $\begin{array}{l}\text { Have you } \\
\text { studied } \\
\text { with your } \\
\text { friend } \\
\text { together in } \\
\text { the last } 7 \\
\text { days? } \\
1=\text { Yes } \\
2=\text { No }\end{array}$ & $\begin{array}{l}\text { Have you } \\
\text { played } \\
\text { with your } \\
\text { friend } \\
\text { together in } \\
\text { the last } 7 \\
\text { days? } \\
1=\text { Yes } \\
2=\text { No }\end{array}$ & $\begin{array}{l}\text { Did you } \\
\text { go to visit } \\
\text { any place } \\
\text { with your } \\
\text { friend in } \\
\text { the last } 7 \\
\text { days? } \\
1=\text { Yes } \\
2=\text { No }\end{array}$ & $\begin{array}{l}\text { Did you } \\
\text { discuss } \\
\text { about any } \\
\text { problem } \\
\text { with your } \\
\text { friend in } \\
\text { the last } 7 \\
\text { days? } \\
1=\text { Yes } \\
2=\text { No }\end{array}$ & 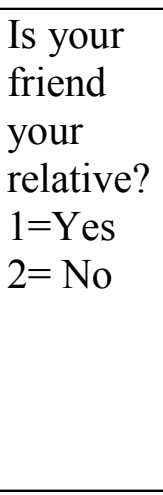 & $\begin{array}{l}\text { What time } \\
\text { you need } \\
\text { to go on } \\
\text { foot to } \\
\text { your } \\
\text { friend's } \\
\text { house? } \\
\text { (please } \\
\text { write in } \\
\text { minutes) }\end{array}$ \\
\hline 1 & & & & & & & & & & \\
\hline 2 & & & & & & & & & & \\
\hline 3 & & & & & & & & & & \\
\hline 4 & & & & & & & & & & \\
\hline 5 & & & & & & & & & & \\
\hline 8 & & & & & & & & & & \\
\hline 9 & & & & & & & & & & \\
\hline 10 & & & & & & & & & & \\
\hline
\end{tabular}


Answer the following questions using Tick mark.

1. Do you go for private tuition?

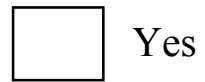

2. Who teaches you at home?
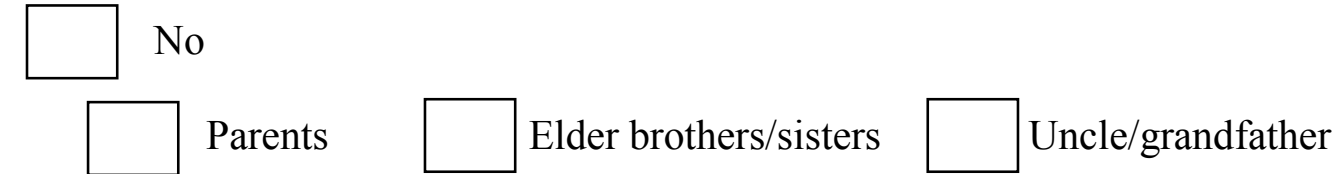

3. What marks did you get in your last annual examination? Please write down in the boxes below.
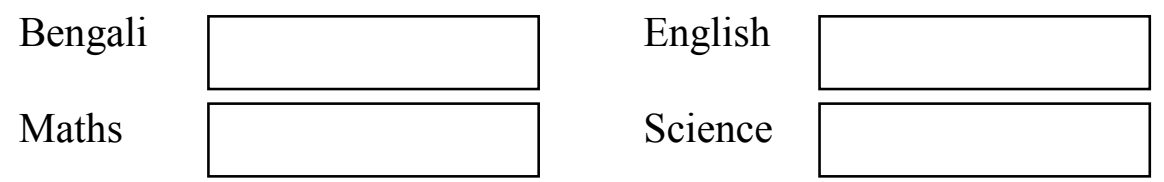

\section{For Muslim students}

4. (For both boy and girl students) Do you pray?

5. (For boy students) Do you go to mosque for prayers?

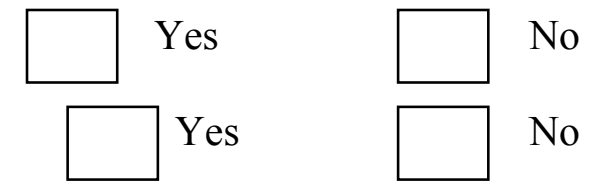

6. (For boy students) If your answer is 'Yes' to the Question 5. Do you go to mosque for prayers regularly?

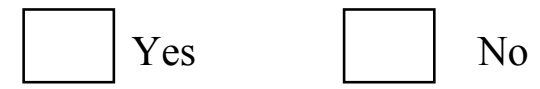

7. (For boy students) Who do you go to mosque with?

$\square$ On your own

With father/grandfather/brother

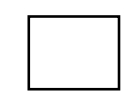

With Friend

Others

8. Do you learn Arabic?
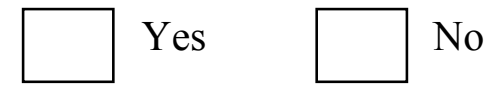

9. If your answer is 'Yes' to the Question 8. What time do you spend in learning Arabic each day?

10. Do you fast in the fasting month (Ramadan)?
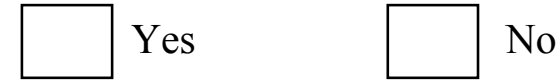
For Hindu students (both Boys and Girls)

11. Do you pray?

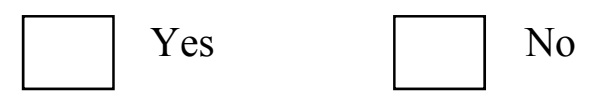

12. Do you go to temple?

Yes

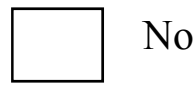

13. If your answer is 'Yes' to the Question 12. Who do you go to temple with?

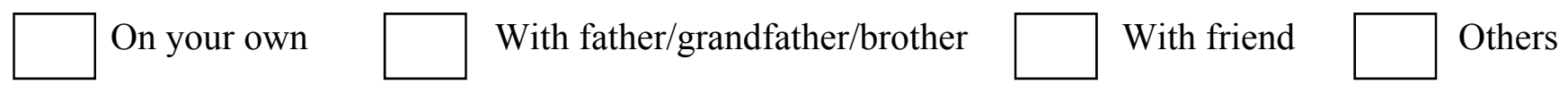

14. Do you study religious staff?

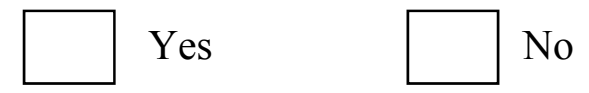

15. If your answer is 'Yes' to the Question 14. What time do you spend for religious study each day? Hour 


\section{Individual Pre-Experiment Math Test (IPEMT)}

Direction: Please answer ALL of the following questions. You will get 5 (five) marks for each correct answer. Total time is 1 hour and 30 minutes.

Name of the Student:

Name of the Father:

Name of the Mother:

Class:

Roll No:

Please start answering from here.

1. In a case, the dividend is 7363 , quotient is 49 and remainder is 13 . What is the divisor?
a) 130
b) 140
c) 150
d) 160

2. Write the smallest number using the digits $2,3,6,1$ ?
a) 2326
b) 1236
c) 6321
d) 1362 
3. The price of a book is 17 Taka. What would be the total price of three of these books?
a) 50 Taka
b) 51 Taka
c) 61 Taka
d) 71 Taka

4. Which number is divisible by $1,3,6,9$ ?
a) 19
b) 20
c) 17
d) 18

5. Calculate the L.C.M. of 25 and 30.
a) 300
b) 200
c) 150
d) 250

6. $28+7=3+8-20$. What is this called?
a) Number
b) Symbol
c) Number series
d) Mathematical statement

7. Which number needs to be added with 37 to get a sum of 50 ?
a) 13
b) 14
c) 5
d) 12 
8. How many types of triangles are there based on the sides?
a) 2
b) 3
c) 4
d) 5

9. What does the symbol $\leq$ mean?
a) Smaller
b) Greater
c) Equal
d) Smaller and equal

10. What is the previous number to the smallest number with three digits?
a) 101
b) 112
c) 99
d) 100

11. What is the sum of the place values of $4,7,2$ in the number of 947231 ?
a) 47231
b) 47200
c) 40072
d) 4720

12. What are the symbols of greater and smaller?
a) $>,=$
b) $<$, =
c) $>,<$
d) None of the above 
13. Sum of three numbers is 9890 . Two of these numbers are 620 and 1260 . What is the third number?
a) 8100
b) 590
c) 8010
d) 8770

14. How many hours are equal to 5 weeks 6 days 9 hours?
a) 993 hours
b) 990 hours
c) 940 hours
d) 949 hours

15. 1 Mon = how many Ser?
a) $56 \mathrm{Ser}$
b) $40 \mathrm{Ser}$
c) $39 \mathrm{Ser}$
d) $45 \mathrm{Ser}$ 


\section{Appendix 2: Group General Knowledge Test (GGKT)}

Direction: Please answer ALL of the following questions. You will get 1 (one) mark for each correct answer. Total time is 20 minutes.

1. Which of the following is the independence day of Bangladesh?
a) 21 February
b) $26 \mathrm{March}$
c) 17 April
d) 16 December

2. In terms of population, what is the position of Bangladesh in the world?
a) 5 th
b) 7 th
c) 8 th
d) 10 th

3. Which is the longest sea beach in the world?
a) Cox's Bazar
b) Kuakata
c) Deegha
d) Pataya

4. Which is the greatest delta in the world?
a) India
b) China
c) Bangladesh
d) Australia

5. What is the area of Bangladesh?
a) $54501 \mathrm{sq}$ miles
b) $56501 \mathrm{sq}$ miles
c) $57401 \mathrm{sq}$ miles
d) $58501 \mathrm{sq}$ miles

6. Which is the oldest place in Bengal?
a) Horikel
b) Samatal
c) Pundra
d) Rarh

7. Which of the following district was called 'Jahanabad'?
a) Satkhira
b) Khulna
c) Dhaka
d) Barisal

8. Which of the following is regarded as the national children day of Bangladesh?
a) 17 January
b) 17 February
c) 17 March
d) 17 April

9. Who is the only Nobel Prize winner of Bangladesh?
a) Joynul Abedin
b) Kamrul Hassan
c) Dr. Muhammad Younus
d) Kazi Nazrul Islam

10. For which book did Rabindranath Tagore win the Nobel Prize?
a) Sonar Tori
b) Geetanjali
c) Sanchaeeta
d) Balaka

11. Who is the first Everest Winner of Bangladesh?
a) Musa Ibrahim
b) Sajal Khaled
c) Sakib Al Hassan
d) Mohammad Ashraful 
12. Which of the following is not a part of folk music of Bangladesh?
a) Baul music
b) Keertan music
c) Jari music
d) Band music

13. What is the national sport event of Bangladesh?
a) Football
b) Cricket
c) Hockey
d) Kabadi

14. Which country is the maximum winner of World Cup Cricket?
a) India
b) Pakistan
c) Australia
d) England

15. Which country was the winner of 2010 World Cup Football?
a) Brazil
b) Argentina
c) Italy
d) Spain

16. Which is the first artificial Earth satellite?
a) Asterix
b) Sputnik 1
c) Sputnik 2
d) Apollo 11

17. How many continents are there in the world?
a) 5
b) 6
c) 7
d) 9

18. In terms of population, which is the largest continent in the world?
a) America
b) Asia
c) Europe
d) Africa

19. Which is the longest river in the world?
a) Padma
b) Jamuna
c) Hoangho
d) Yangsikian

20. Which part of Asia is Bangladesh situated?
a) North-East
b) South-East
c) North-West
d) South-West 


\section{Appendix 3: Group Math Test (GMT)}

Direction: Please complete the following maths problems.

Problem 1: Arrange the numbers in the following Table in Ascending and Descending order using symbol. One is done for you.

\begin{tabular}{|l|l|l|}
\hline Number & Ascending & Descending \\
\hline $65032,8973,26940,53278$, & $8973<9856<26940<$ & $84256>80149>65032>$ \\
$80149,84256,9856$ & $53278<65032<80149<$ & $53278>26940>9856>$ \\
& 84256 & 8973 \\
\hline $\begin{array}{l}88457,45682,23412, \\
780021,100000,45789,\end{array}$ & \\
65231 & & \\
& & \\
\hline $\begin{array}{l}78921,12356,98213, \\
238593,45123,636336, \\
24789\end{array}$ & & \\
& & \\
\hline $\begin{array}{l}9874,87412,23145,89564, \\
98741,45621,32100\end{array}$ & & \\
& & \\
$654646,3265,7841565$, & & \\
$568984,56874,89586$, & & \\
656898 & & \\
& & \\
\hline
\end{tabular}

Problem 2: Without repeating any digit, arrange the following groups of numbers to make the greatest and smallest numbers possible. Calculate the difference between the greatest and smallest number in each set.
(a) $7,2,3,0,1$
(b) $4,2,3,8,1$
(c) $6,0,7,8,5$
(d) $2,3,7,0,9$ 
Problem 3: Here is part of a wall chart that lists numbers from 1 to 100.

\begin{tabular}{||l|l|l|l|l|l|l|l|l|l||}
\hline 1 & 2 & 3 & 4 & 5 & 6 & 7 & 8 & 9 & 10 \\
\hline 11 & 12 & 13 & 14 & 15 & 16 & 17 & 18 & 19 & 20 \\
\hline 21 & 22 & 23 & 24 & 25 & \multicolumn{1}{|l|}{$\mid$} \\
\hline
\end{tabular}

Below is part of the same wall chart.

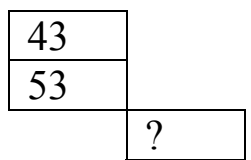

Look at the charts carefully and find out what number should be in the box with the question mark inside. How do you find this?

Problem 4: In which pair of numbers is the second number 100 more than the first number? Please show how you solve this problem.
A. 199 and 209
B. 4236 and 4246
C. 9635 and 9735
D. 51863 and 52863

Problem 5: Ajay wanted to use his calculator to add 1463 and 319. He entered $1263+319$ by mistake. What could he do to correct his mistake?
A. Add 20
B. Add 200
C. Subtract 200
D. Subtract 20

Please show how you solve this problem.

Problem 6: Rahim had 100 mangoes. He sold some and then had 50 left. $\square$ represents the number of mangoes that he sold. Which of these is a number sentence that shows this?
A. $\square-50=100$
B. $50-\square=100$
C. $\square-100=50$
D. $100-\square=50$

Problem 7: Rahim had 100 mangoes. He sold some and then had 50 left. He found some rotten mangoes and threw them away. Finally he had 45 mangoes left. $\square$ represents the number of mangoes that he sold and \# represents the number that was rotten. Which of these is a number sentence that shows this?
A. $\square+50-\#=100$
B. $\square+50+\#=100$
C. $\square+45+\#=100$
D. $100-\square=45$ 
Problem 8: The sum of ages of a mother and a daughter is 65 years. The mother's age is 4 times as much as the daughter's. What are the ages of the mother and the daughter? What will be their ages after 6 years?

Problem 9: Tina has Tk. 125 more than Bina and Tk. 45 less than Rina. Tina has Tk. 300. How much does each of Bina and Rina have? How much do the three persons have altogether?

Problem 10: In 2012, there were 95 members in a cooperative society. In 201325 new members joined in the society. Each of the members has paid 200 for a picnic in 2013 . How much money was collected as subscription? 


\section{Appendix 4: Individual Post-Experiment Math Test (IPOMT)}

Direction: Please answer ALL of the following questions. You will get 5 (five) marks for each correct answer. Total time is 1 hour and 30 minutes.

Name of the Student:

Name of the Father:

Name of the Mother:

Class:

Roll No:

Please start answering from here.

Problem 1: Arrange the following numbers in Ascending and Descending order using symbol.

$5238,4132,8725,6138,7201$

Problem 2: Without repeating, arrange the following digits to make the smallest number possible.

\section{$4,3,9,1$}

Problem 3: Subtract the greatest number with 3 digits from the smallest number with 5 digits.

Problem 4: The difference between two numbers is 425 . If the greater number is 7235 , find out the smaller number.

Problem 5: When you subtract one of the following numbers from 900, the answer is greater than 300 . Which number is it?
A. 823
B. $\quad 712$
C. $\quad 667$
D. 579 
Problem 6: What is 3 times 23?
A. 323
B. 233
C. 69
D. 26

Problem 7: Mr. Rahim drew eight 100 Taka notes, four 50 Taka notes and two 10 Taka notes from the bank. What is the amount he drew from the bank?

Problem 8: Fill the blank in the following number sentence.

$2000+$ $+30+9=2739$

Problem 9: Kamal had 50 mangoes. He sold some and then had 20 left. Which of these is a number sentence that shows this?
A. $\square-20=50$
B. $20-\square=50$
C. $\square-50=20$
D. $50-\square=20$

Problem 10: If we equally distribute Taka 7642 among 52 people, how much will each of them receive? What will be the remaining amount? 


\section{Appendix 5: Network Centrality Measures}

\subsection{Definitions}

In this appendix, we give the formal definition of the centrality measures used in the paper. We consider a finite set of individuals (or nodes) $N=\{1, \ldots, n\}$ who are connected in a network. A network (or graph) is a pair $(N, \mathbf{g})$, where $\mathbf{g}$ is a network on the set of nodes $N$. A network $\mathbf{g}$ is represented by an $n \times n$ adjacency matrix $\mathbf{G}$, with entry $g_{i j}$ denoting whether $i$ is linked to $j$ and can also include the intensity of that relationship. In this paper, we consider indegree weighted directed networks, which are defined in Section 4.

The distance $\delta_{i j}(\mathbf{g})$ between two nodes $i$ and $j$ in the same component of a network $\mathbf{g}$ is the length of a shortest path (also known as a geodesic) between them.

The diameter is the largest distance between two nodes $i$ and $j$ in a network $\mathbf{g}$, i.e. $\max \delta_{i j}(\mathbf{g}), \forall i, j$.

The neighbors of a node $i$ in a network $(N, \mathbf{g})$ are denoted by $N_{i}(\mathbf{g})$.

The degree of a node $i$ in a network $(N, \mathbf{g})$ is the number of neighbors that $i$ has in the network, i.e., $\left|N_{i}(\mathbf{g})\right|$. As a result, the degree centrality is the degree of node $i$ divided by the number of feasible links, i.e.,

$$
d_{i}(\mathbf{g})=\frac{\left|N_{i}(\mathbf{g})\right|}{n-1}=\frac{\sum_{j=1}^{n} g_{i j}}{n-1}
$$

It has values in $[0,1]$.

The betweenness centrality a measure of a node's centrality in a given network. It is equal to the number of shortest paths from all nodes to all others that pass through that node. It is calculated as follows:

$$
B_{i}(\mathbf{g})=\frac{1}{(n-1)(n-2)} \sum_{j=1}^{n} \sum_{k=1}^{n} \frac{m_{j k}^{i}(\mathbf{g})}{m_{j k}(\mathbf{g})},
$$

where $m_{j k}(\mathbf{g})$ is the number of shortest paths between node $j$ and node $k$ in network $\mathbf{g}$ and $m_{j k}(\mathbf{g})$ is the number of shortest paths between node $j$ and node $k$ trough $i$ in network $\mathbf{g}$. It has values in $[0,1]$.

The closeness centrality is defined as follows:

$$
C_{i}(\mathbf{g})=\frac{n-1}{\sum_{j \neq i} \delta_{i j}(\mathbf{g})}
$$


where $\delta_{i j}(\mathbf{g})$ is the shortest path between nodes $i$ and $j$ in network $\mathbf{g}$. It has values in $[0,1]$.

The eigenvector centrality is defined using the following recursive formula:

$$
v_{i}(\mathbf{g})=\frac{1}{\lambda_{1}} \sum_{j=1}^{n} g_{i j} v_{j}(\mathbf{g})
$$

where $\lambda_{1}$ is the largest eigenvalue of $\mathbf{G}$. By the Perron-Frobenius theorem, using the largest eigenvalue guarantees that $v_{i}$ is always positive. Eigenvector centrality $v_{i}(\mathbf{g})$ is the leading eigenvector of $\mathbf{G}$. This centrality measure is different from the others above because, in measuring a node's centrality, it gives a specific weight to each connected node by considering its relevance in terms of centrality. In matrix form, we have:

$$
\lambda_{1} \mathbf{v}(\mathbf{g})=\mathbf{G v}(\mathbf{g})
$$

The Katz-Bonacich centrality is a generalization of (10), which allows the Katz-Bonacich centrality to depend on a parameter $\phi$. We have:

$$
b_{i}(\phi, \mathbf{g})=1+\phi \sum_{j=1}^{n} g_{i j} b_{j}(\phi, \mathbf{g})
$$

where $\phi<1 / \lambda_{\max }(\mathbf{G})$, where $\lambda_{\max }(\mathbf{G})$ is the spectral radius of $\mathbf{G}$. The parameter $\phi$ is usually interpreted as a discount factor of each node. In matrix form, we have:

$$
\mathbf{b}(\phi, \mathbf{g})=\mathbf{1}_{n}+\phi \mathbf{G} \mathbf{b}(\phi, \mathbf{g})
$$

where $\mathbf{1}_{n}$ is a $n$-vector of 1 . The Katz-Bonacich centrality has a closed form solution, which is:

$$
\mathbf{b}(\phi, \mathbf{g})=\left(\mathbf{I}_{n}-\phi \mathbf{G}\right)^{-1} \mathbf{1}_{n}
$$

where $\mathbf{I}_{n}$ is the $n \times n$ identity matrix. The condition $\phi<1 / \lambda_{\max }(\mathbf{G})$ guarantees that $\left(\mathbf{I}_{n}-\phi \mathbf{G}\right)$ is invertible.

We show below that the Katz-Bonacich centrality can be obtained as a Nash equilibrium of a network game. The key player centrality captures instead a normative view of centrality.

\subsection{Foundation of centrality measures}

Consider a simple game on networks with strategic complementarities (Jackson and Zenou, 2015). Following Calvó-Armengol and Zenou (2004) and Ballester et al. (2006), consider the following linear-quadratic utility function

$$
u_{i}(\mathbf{y}, \mathbf{g})=\alpha_{i} y_{i}-\frac{1}{2} y_{i}^{2}+\phi \sum_{j=1}^{n} g_{i j} y_{i} y_{j}
$$


where each student $i$ decides how much effort $y_{i} \in \mathbb{R}_{+}$to exert in terms of education (i.e. how many hours to study) given the network $\mathbf{g}$ she belongs to. In (15), $\alpha_{i}$ captures the observable characteristics of student $i$ (gender, parent's education, etc.) and $\phi>0$ is the intensity of interactions between students. Remember that $g_{i j}=1$ if two students are friends and zero otherwise. In our weighted directed network, $g_{i j} \in[0,1]$ if $j$ has nominated $i$ as his/her friend, and $g_{i j}=0$, otherwise, where the weight $g_{i j}$ is given by (1). Ballester et al. (2006) have shown that, if $\phi<1 / \lambda_{\max }(\mathbf{G})$, then there exists a unique interior Nash equilibrium of this game with utility (15), which is given by:

$$
\mathbf{y}^{*} \equiv \mathbf{y}^{*}(\mathbf{g})=\mathbf{b}_{\alpha}(\phi, \mathbf{g})
$$

where $\mathbf{b}_{\boldsymbol{\alpha}}(\phi, \mathbf{g})$ is the weighted Katz-Bonacich centrality defined as:

$$
\mathbf{b}_{\boldsymbol{\alpha}}(\phi, \mathbf{g})=\left(\mathbf{I}_{n}-\phi \mathbf{G}\right)^{-1} \boldsymbol{\alpha}=\sum_{k=0}^{\infty} \phi_{1}^{k} \mathbf{G}^{k} \boldsymbol{\alpha}
$$

Observe that (17) is just a generalization of (14) when, $\mathbf{1}_{n}$, the $n$-vector of 1 , is replaced by $\boldsymbol{\alpha}$, the $n$-vector of $\alpha_{i}$. This result shows that, in any game with strategic complementarities and linear-quadratic utility function where agents choose effort, there is a unique Nash equilibrium in pure strategies such that each agent provides effort according to her KatzBonacich centrality. This is gives a micro-foundation for the Katz-Bonacich centrality. ${ }^{8}$

Let us now define the key-player centrality. For that, consider the game with strategic complements developed above for which the utility is given by (15) and denote $Y^{*}(\mathbf{g})=\sum_{i=1}^{n} y_{i}^{*}$ the total equilibrium level of activity in network $\mathbf{g}$, where $y_{i}^{*}$ is the Nash equilibrium effort given by (16). Also denote by $\mathbf{g}^{[-i]}$ the network $\mathbf{g}$ without individual $i$. Then, in order to determine the key player, the planner will solve the following problem:

$$
\max \left\{Y^{*}(\mathbf{g})-Y^{*}\left(\mathbf{g}^{[-i]}\right) \mid i=1, \ldots, n\right\}
$$

Assume that $\phi<1 / \lambda_{\max }(\mathbf{G})$. Then, the intercentrality or the key-player centrality $c_{i}(\phi, \mathbf{g})$ of agent $i$ is defined as follows:

$$
c_{i}(\phi, \mathbf{g})=\frac{b_{\alpha_{i}}(\phi, \mathbf{g}) b_{1_{i}}(\phi, \mathbf{g})}{m_{i i}}
$$

\footnotetext{
${ }^{8}$ Dequiedt and Zenou (2014) propose an axiomatic approach to derive the degree, eigenvector and KatzBonacich centralities. In other words, they show which axioms are crucial to characterize centrality measures for which the centrality of an agent is recursively related to the centralities of the agents she is connected to (this includes the degree, eigenvector and Katz-Bonacich centralities).
} 
where $m_{i i}$ is the $(i, i)$ cell of matrix $\mathbf{M}\left(\mathbf{g}, \phi_{1}\right)=\left(\mathbf{I}_{n}-\phi \mathbf{G}\right)^{-1}, b_{\alpha_{i}}(\phi, \mathbf{g})$ and $b_{1_{i}}(\phi, \mathbf{g})$ is the weighted and unweighted Katz-Bonacich centrality of agent $i$. Ballester et al. $(2006,2010)$ have shown that the player $i^{*}$ that solves (18) is the key player if and only if $i^{*}$ is the agent with the highest intercentrality in $\mathbf{g}$, that is, $c_{i^{*}}(\phi, \mathbf{g}) \geq c_{i}(\phi, \mathbf{g})$, for all $i=1, \ldots, n$. The intercentrality measure (19) of agent $i$ is the sum of $i$ 's centrality measures in $\mathbf{g}$, and $i$ 's contribution to the centrality measure of every other agent $j \neq i$ also in $\mathbf{g}$. It accounts both for one's exposure to the rest of the group and for one's contribution to every other exposure. This means that the key player $i^{*}$ in network $\mathbf{g}$ is given by $i^{*}=\arg \max _{i} c_{i}(\phi, \mathbf{g})$, where

$$
c_{i}(\phi, \mathbf{g})=Y^{*}(\mathbf{g})-Y^{*}\left(\mathbf{g}^{[-i]}\right) \text {. }
$$

As a result, we can rank all students in our networks by their intercentrality or key-player centrality using the formula (19) or (20).

\subsection{Parameter choice for the Katz-Bonacich and the key-player centrality}

The parameter $\phi$ is crucial in any empirical application since the centrality ranking in a given network is sensitive to this parameter's choice. It can be obtained by estimating a spatial model (as in Calvó-Armengol et al., 2009 or Liu et al., 2014). However, such estimation is unreliable with small networks and depends on the available covariates. We rely on a simple heuristic algorithm that mimics our theoretical model (given in Section 5.2), where given linear-quadratic preferences (15), individual effort in a network is equal to her Katz-Bonacich centrality (see (16)). Indeed, for each network $r=1, \cdots, R$, with $N_{r}$ members each, we need to find a $\phi_{r}$ such that the Euclidean distance between the Grade Point Average or GPA of a student $i$ (which measures $y_{i}^{*}$ in our model; see Calvó-Armengol et al., 2009) and her Katz-Bonacich centrality is minimized. For each network $r$, a grid search is performed to find $\phi_{r}$ such that:

$$
\min _{\phi_{r}}\left\{\sum_{i=1}^{N_{r}}\left[y_{i, r}^{*}-b_{\alpha_{i}}\left(\phi_{r}, \mathbf{g}\right)\right]^{2}\right\}, \quad r=1, \cdots, R
$$

where $b_{\alpha_{i}}(\phi, \mathbf{g})$ is defined by (17). Once each parameter $\phi_{r}$ that satisfies the problem (21) is found, individual Katz-Bonacich and key-player centralities can be calculated in each network using formulas (17) and (19), respectively. 


\section{Appendix 6: Games played by students}

\subsection{Risk taking game}

We put 5 pencils in a jar of which one pencil has a red mark on the bottom. The rest do not have a red mark. Students cannot see the mark on the pencil until they take it out of the jar. They decide how many pencils to take out of the jar. They get to keep ALL the pencils they take, if there is no red mark on any pencil. But if there is a red mark on ANY pencil, that they take, they have to give ALL the pencils back and stop taking pencils. Students are asked to write their answer in the answer sheet.

\subsection{Time preference game}

This game asks students to make some choices about candy. It is clearly communicated that there is no right or wrong answer in this game, we just want them to put down what they would actually choose. There are going to be 4 rounds. In each round, they are asked to choose a candy-plate between two plates. They decide which plate of candy they want. Some of the plates, they can have TOMORROW, but some of the plates, they can have AFTER TWO DAYS. If they choose a plate for TOMORROW, they will get it TOMORROW from their teacher. If they choose a plate for AFTER TWO DAYS, they will get it AFTER TWO DAYS from their teacher. At the end of the 4 rounds, only one of the rounds will be the round-that-counts and they will get to take that choice home. At the end, we toss to determine which of the 4 rounds is the round-that-counts. Since they don't know which round will count, they were told that they should make decision in each round as if it is the round that counts.

\subsection{Competition game}

Students are asked to calculate the sum of three randomly chosen two-digit numbers. They are given 5 minutes to do as many sums as possible. They can choose one of two payment options for this task. If a student chooses Option 1, s/he gets 1 candy for each problem that $\mathrm{s} /$ he solves correctly in the 5 minutes. His/her payment does not decrease if $\mathrm{s} /$ he provides an incorrect answer to a problem. If $\mathrm{s} /$ he chooses Option 2, s/he is randomly paired with another person and his/her payment depends on his/her performance relative to that of the person that $\mathrm{s} /$ he is paired with. If $\mathrm{s} /$ he solves more problems correctly than the person $\mathrm{s} /$ he is paired with, $\mathrm{s} /$ he receives 2 candies per correct answer. If both of them solve the same number of problems they will receive 1 candy per correct answer. If $\mathrm{s} /$ he solves 
less than the person s/he is paired with, s/he will not receive any candy. The students are not allowed to use a calculator to do the sums; however they are allowed to make use of the provided scratch paper.

Students are asked to choose between two different payment schemes. Option 1 is a piece rate which pays a candy for every sum correctly completed. In option 2 , payments are determined in a competitive way. Each student participant is randomly and anonymously paired with someone else in the classroom. S/he is paid two candies for every sum correctly completed if $\mathrm{s} /$ he completes more sums correctly than the person with whom $\mathrm{s} /$ he is paired, one candy if both participants complete the same amount of correct sums, and no candy if $\mathrm{s} /$ he loses the competition. 
Figure 1: Regions where the experiments were conducted

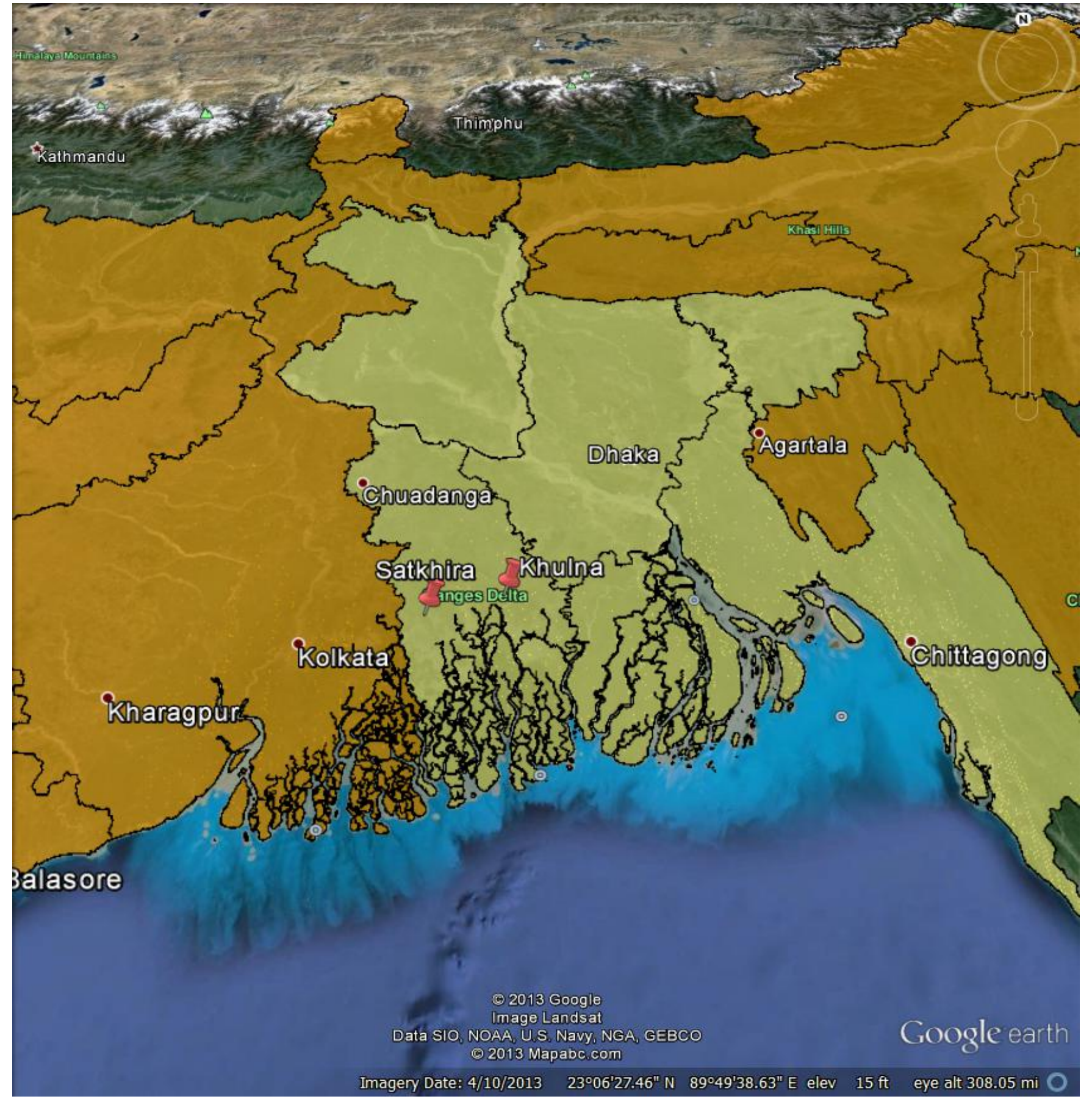




\section{Figure 2: Timeline of the experiment}

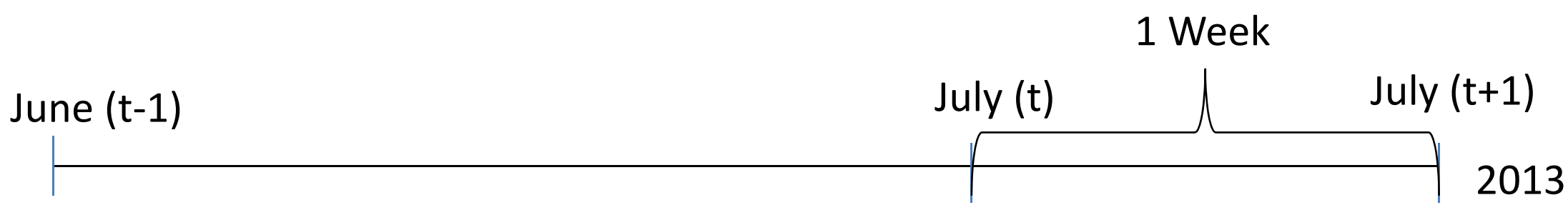
(1) Network survey
(2) Household survey
(3) Ind. math test (IPEMT)

(1) Study groups formed

(2) Group test on general knowledge (GGKT)

(3) Group math test (GMT) to be handed over in one week
(1) Ind. math test (IPOMT)

(2) Prizes given 
Figure 3: Number of friends within a group

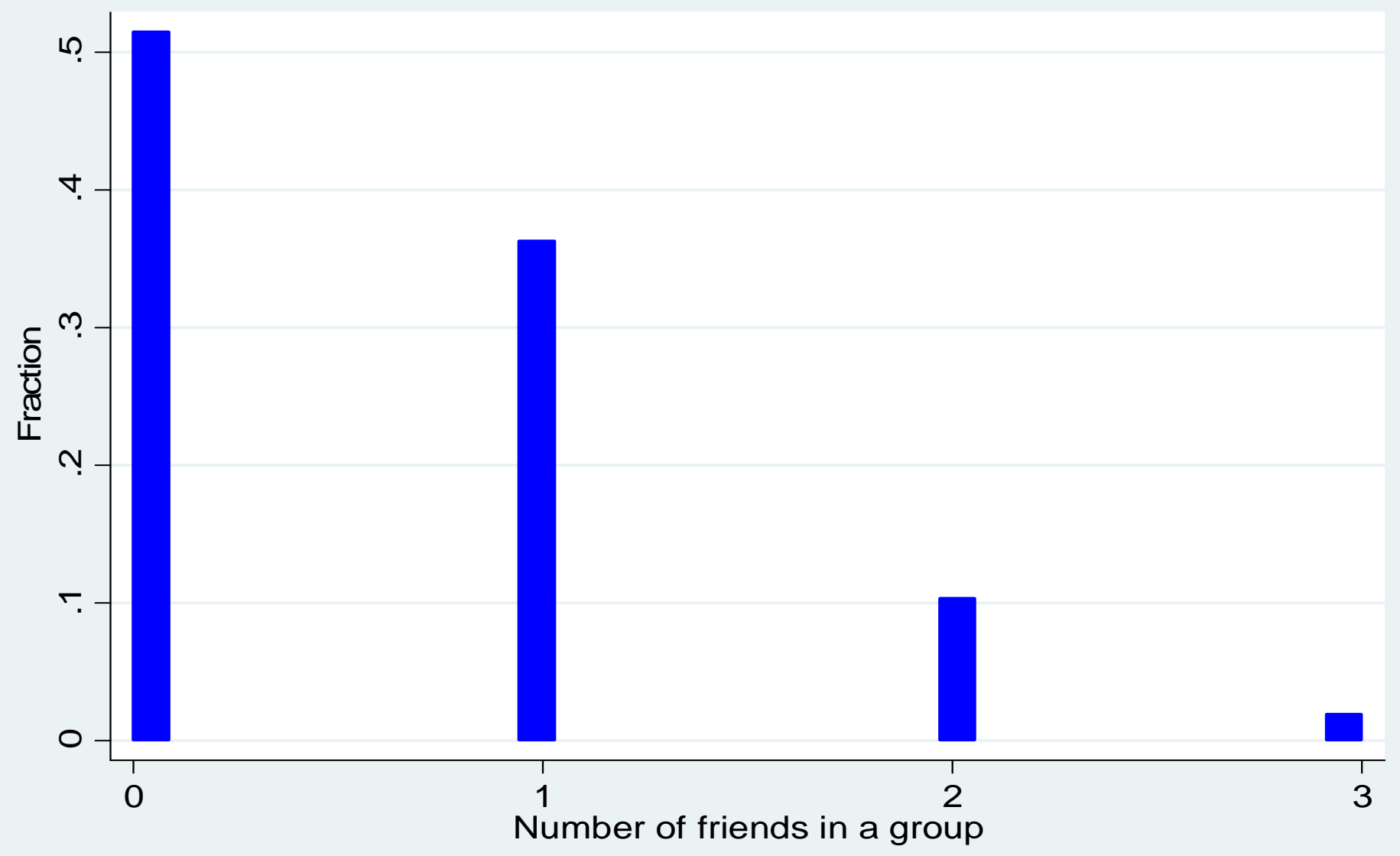


Figure 4: Number of friendship links within a group

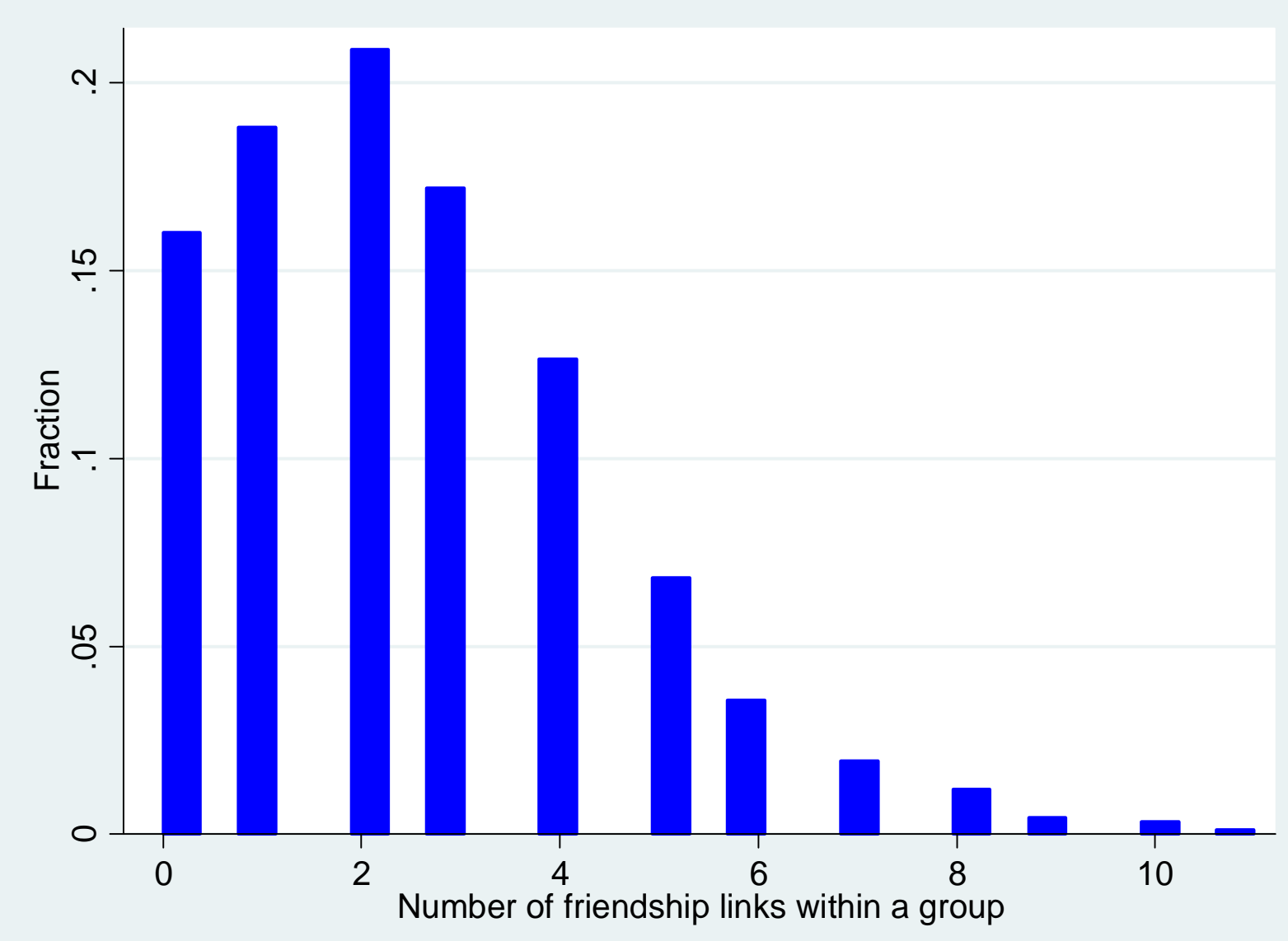


Figure 5: Distribution of group-average network centrality ( $N=924)$
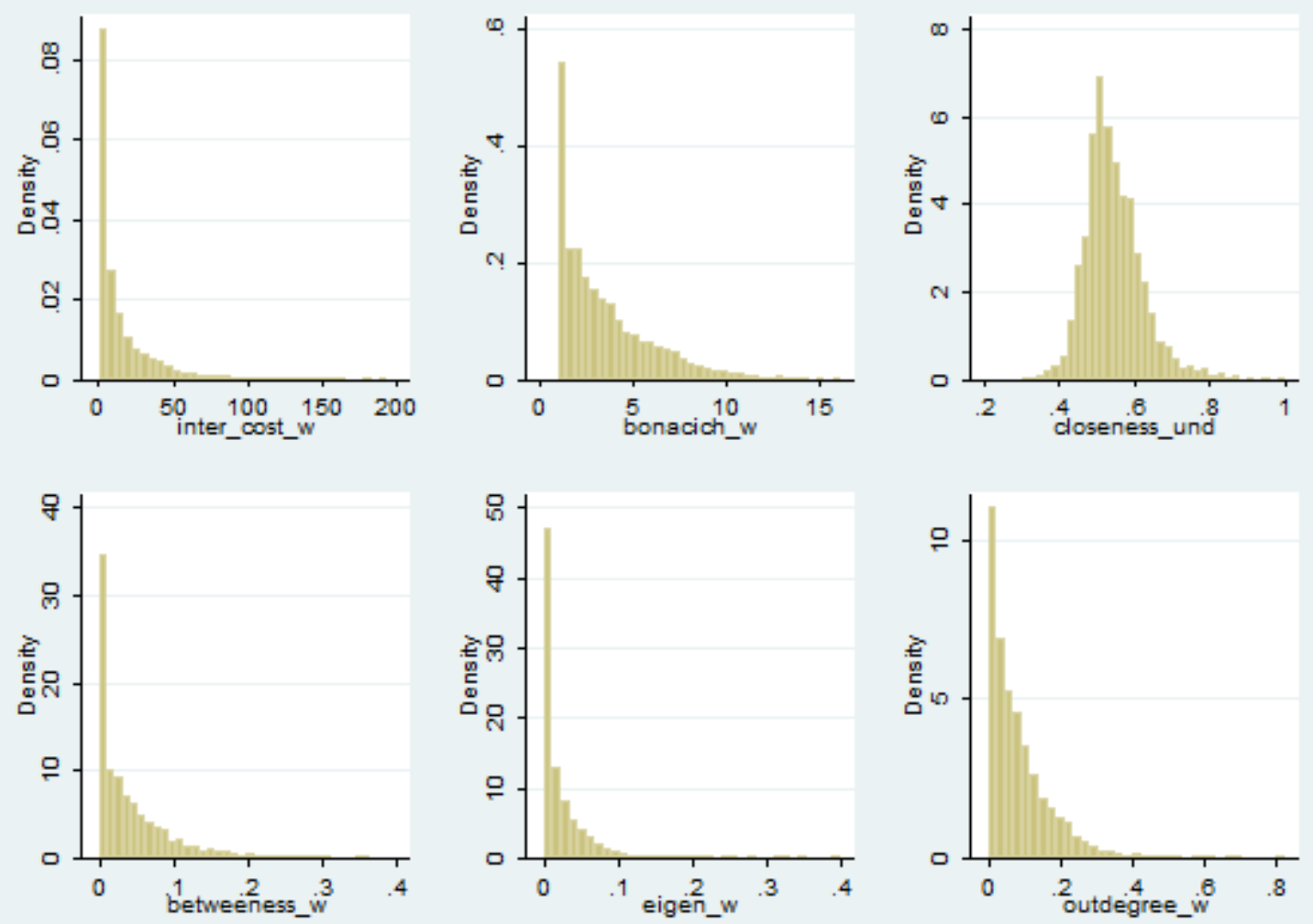
Table 1: Descriptive statistics of individual and group characteristics

\begin{tabular}{lccccc}
\hline & Obs & Mean & Std. Dev. & Min & Max \\
\hline & & & & & \\
Individual characteristics & & & & & \\
Missing IPEMT & 3406 & 0.153 & 0.360 & 0 & 1 \\
Female & 3406 & 0.508 & 0.500 & 0 & 1 \\
Household income per cap & 3406 & 4297.603 & 836.862 & 921.182 & 10000 \\
Household has electricity & 3406 & 0.280 & 0.449 & 0 & 1 \\
Parent education in years & 3406 & 4.939 & 3.741 & 0 & 17 \\
Parent age & 3406 & 39.673 & 6.760 & 22.5 & 80 \\
& & & & & \\
Performance indicators & & & & & \\
Individual pre-experiment math test (IPEMT) & 3406 & -0.003 & 1.003 & -2.322 & 2.727 \\
Individual post-experiment math test (IPOMT) & 3406 & 0.003 & 1.002 & -1.578 & 2.364 \\
Group score on general knowledge (GGKT) & 924 & -0.002 & 1.006 & -2.811 & 3.054 \\
Group score on math assignment (GMT) & 924 & -0.036 & 1.020 & -2.863 & 1.969 \\
& & & & & \\
\hline
\end{tabular}

Table 2a: Descriptive statistics of individual centrality measures and network characteristics

\begin{tabular}{lccccc}
\hline & Obs & Mean & Std. Dev. & Min & Max \\
\hline & & & & & \\
Panel A: Student level & & & & & \\
Intercentrality & 3406 & 15.753 & 22.22 & 1 & 194.01 \\
Katz-Bonacich & 3406 & 3.460 & 2.500 & 1 & 16.12 \\
Closeness & 3406 & 0.546 & 0.078 & 0 & 2.51 \\
Betweeness & 3406 & 0.042 & 0.051 & 0 & 0.36 \\
Eigenvector & 3406 & 0.022 & 0.032 & 0 & 0.40 \\
Degree & 3406 & 0.085 & 0.086 & 0 & 0.83 \\
& & & & & \\
Panel B: Network level & & & & & \\
Size & 80 & 51.637 & 21.712 & 25 & 125 \\
Density & 80 & 0.207 & 0.069 & 0.071 & 0.42 \\
Path length & 80 & 1.740 & 0.170 & 1.314 & 2.18 \\
Diameter & 80 & 4.713 & 1.105 & 1 & 8 \\
& & & & & \\
\hline
\end{tabular}


Table 2b: Descriptive on average, maximum and minimum centrality measures

\begin{tabular}{lccccc}
\hline & Obs & Mean & Std. Dev. & Min & Max \\
\hline Avg Intercentrality & 924 & 15.69 & 11.62 & 1 & 95.98 \\
Max Intercentrality & 924 & 36.35 & 30.98 & 1 & 194.01 \\
Min Intercentrality & 924 & 3.18 & 3.8 & 1 & 47.98 \\
Avg Katz-Bonacich & 924 & 3.45 & 1.39 & 1 & 9.39 \\
Max Katz-Bonacich & 924 & 5.92 & 2.85 & 1 & 16.12 \\
Min Katz-Bonacich & 924 & 1.63 & 0.83 & 1 & 8.08 \\
& & & & & \\
Avg Closeness & 924 & 0.55 & 0.06 & 0.34 & 0.83 \\
Max Closeness & 924 & 0.1 & 0.38 & 0 & 2.51 \\
Min Closeness & 924 & 0.07 & 0.28 & 0 & 1.84 \\
& & & & & \\
Avg Betweenness & 924 & 0.04 & 0.03 & 0 & 0.19 \\
Max Betweenness & 924 & 0.09 & 0.06 & 0 & 0.36 \\
Min Betweenness & 924 & 0.01 & 0.01 & 0 & 0.13 \\
Avg Eigenvector & & & & & \\
Max Eigenvector & 924 & 0.02 & 0.02 & 0 & 0.20 \\
Min Eigenvector & 924 & 0.05 & 0.04 & 0 & 0.4 \\
Avg Degree & 924 & 0 & 0.01 & 0 & 0.07 \\
Max Degree & & & & & 0.31 \\
Min Degree & 924 & 0.08 & 0.05 & 0 & 0.83 \\
& 924 & 0.16 & 0.11 & 0 & 0.2 \\
& 924 & 0.03 & 0.03 & 0 & \\
\hline
\end{tabular}


Table 3: Effects of average and own centrality on student outcomes

\begin{tabular}{|c|c|c|c|c|}
\hline & $\begin{array}{c}(1) \\
\text { GGKT }\end{array}$ & $\begin{array}{c}(2) \\
\text { GMT }\end{array}$ & $\begin{array}{l}(3) \\
\text { IPOMT }\end{array}$ & $\begin{array}{c}(4) \\
\text { IPOMT }\end{array}$ \\
\hline Avg. Intercentrality & $\begin{array}{l}0.009 \\
(0.003)^{* * *}\end{array}$ & $\begin{array}{l}0.011 \\
(0.002)^{* * *}\end{array}$ & $\begin{array}{l}0.009 \\
(0.001)^{* * *}\end{array}$ & $\begin{array}{l}0.001 \\
(0.001)\end{array}$ \\
\hline Own Intercentrality & & & & $\begin{array}{l}0.008 \\
(0.001)^{* * *}\end{array}$ \\
\hline Avg. Bonacich & $\begin{array}{l}0.082 \\
(0.024) * * *\end{array}$ & $\begin{array}{l}0.093 \\
(0.021)^{* * *}\end{array}$ & $\begin{array}{l}0.085 \\
(0.010)^{* * *}\end{array}$ & $\begin{array}{l}0.010 \\
(0.009)\end{array}$ \\
\hline Own Bonacich & & & & $\begin{array}{l}0.077 \\
(0.006)^{* * *}\end{array}$ \\
\hline Avg. Closeness & $\begin{array}{l}2.450 \\
(0.980)^{* *}\end{array}$ & $\begin{array}{l}2.364 \\
(0.815)^{* * *}\end{array}$ & $\begin{array}{l}1.917 \\
(0.528)^{* * *}\end{array}$ & $\begin{array}{l}0.293 \\
(0.383)\end{array}$ \\
\hline Own Closeness & & & & $\begin{array}{l}1.744 \\
(0.292)^{* * *}\end{array}$ \\
\hline Avg. Betweenness & $\begin{array}{l}-0.307 \\
(0.937)\end{array}$ & $\begin{array}{l}-1.334 \\
(1.049)\end{array}$ & $\begin{array}{l}0.347 \\
(0.674)\end{array}$ & $\begin{array}{l}0.054 \\
(0.529)\end{array}$ \\
\hline Own Betweenness & & & & $\begin{array}{l}0.380 \\
(0.319)\end{array}$ \\
\hline Avg. Eigenvector & $\begin{array}{l}4.915 \\
(1.764)^{* * *}\end{array}$ & $\begin{array}{l}6.709 \\
(1.754)^{* * *}\end{array}$ & $\begin{array}{l}4.654 \\
(1.174)^{* * *}\end{array}$ & $\begin{array}{l}0.698 \\
(0.561)\end{array}$ \\
\hline Own Eigenvector & & & & $\begin{array}{l}4.309 \\
(0.736)^{* * *}\end{array}$ \\
\hline Avg. Degree & $\begin{array}{l}1.668 \\
(0.648)^{* *}\end{array}$ & $\begin{array}{l}2.553 \\
(0.643)^{* * *}\end{array}$ & $\begin{array}{l}2.443 \\
(0.349)^{* * *}\end{array}$ & $\begin{array}{l}0.338 \\
(0.251)\end{array}$ \\
\hline Own Degree & & & & $\begin{array}{l}2.190 \\
(0.216) * * *\end{array}$ \\
\hline
\end{tabular}

Note: The average centrality used in columns (1) to (3) includes myself while the one used in column (4) does not include myself. Each coefficient on average centrality is obtained from a different regression. All regressions control for individual characteristics and school (classroom) fixed effects. $\mathrm{N}=924$ for columns (1) and (3); N=3401 for columns (3) and (4). Standard errors are clustered at the school level. * $\mathrm{p}<0.10$; ** $\mathrm{p}<0.05$; *** $\mathrm{p}<0.01$ 
Table 4: Correlation across network centrality measures

\begin{tabular}{lcccccc} 
& Intercentrality & Bonacich & Closeness & Betweeness & Eigenvector & Degree \\
\hline Intercentrality & 1 & & & & & \\
Bonacich & 0.954 & 1 & & & & \\
Closeness & 0.438 & 0.477 & 1 & & & \\
Betweeness & 0.170 & 0.254 & 0.361 & 1 & & \\
Eigenvector & 0.768 & 0.796 & 0.564 & 0.184 & 1 & 1 \\
Degree & 0.794 & 0.854 & 0.669 & 0.275 & 0.810 & 10 \\
\hline
\end{tabular}

Note: Calculated using the average group centrality of 924 groups in random grouping schools. 
Table 5: Effects of average centrality on group outcomes when two measures are included

\begin{tabular}{|c|c|c|c|c|}
\hline & (1) & $(2)$ & (3) & (4) \\
\hline \multicolumn{5}{|c|}{ Outcome: GGKT (N=924) } \\
\hline \multicolumn{5}{|c|}{ Average centrality in the group based on } \\
\hline Intercentrality & 0.006 & 0.008 & 0.009 & 0.013 \\
\hline & $(0.006)$ & $(0.003)^{* *}$ & $(0.004)^{* *}$ & $(0.004)^{* * *}$ \\
\hline Bonacich & $\begin{array}{l}0.032 \\
(0.066)\end{array}$ & & & \\
\hline Closeness & & $\begin{array}{l}0.877 \\
(1.239)\end{array}$ & & \\
\hline Eigenvector & & & $\begin{array}{l}0.317 \\
(2.097)\end{array}$ & \\
\hline Degree & & & & $\begin{array}{l}-1.376 \\
(1.008)\end{array}$ \\
\hline \multicolumn{5}{|c|}{ Outcome: GGKT (N=924) } \\
\hline Intercentrality & $\begin{array}{l}0.006 \\
(0.006)\end{array}$ & & & \\
\hline Bonacich & $\begin{array}{l}0.032 \\
(0.066)\end{array}$ & $\begin{array}{l}0.070 \\
(0.033)^{* *}\end{array}$ & $\begin{array}{l}0.081 \\
(0.036)^{* *}\end{array}$ & $\begin{array}{l}0.152 \\
(0.052)^{* * *}\end{array}$ \\
\hline Closeness & & $\begin{array}{l}0.788 \\
(1.334)\end{array}$ & & \\
\hline Eigenvector & & & $\begin{array}{l}0.131 \\
(2.124)\end{array}$ & \\
\hline Degree & & & & $\begin{array}{l}-2.346 \\
(1.311)^{*}\end{array}$ \\
\hline \multicolumn{5}{|c|}{ Outcome: GMT (N=924) } \\
\hline Intercentrality & $\begin{array}{l}0.015 \\
(0.009)\end{array}$ & $\begin{array}{l}0.011 \\
(0.003)^{* * *}\end{array}$ & $\begin{array}{l}0.008 \\
(0.004)^{* *}\end{array}$ & $\begin{array}{l}0.010 \\
(0.004)^{* *}\end{array}$ \\
\hline Bonacich & $\begin{array}{l}-0.035 \\
(0.088)\end{array}$ & & & \\
\hline Closeness & & $\begin{array}{l}0.199 \\
(1.021)\end{array}$ & & \\
\hline Eigenvector & & & $\begin{array}{l}2.476 \\
(2.650)\end{array}$ & \\
\hline Degree & & & & $\begin{array}{l}0.192 \\
(1.306)\end{array}$ \\
\hline
\end{tabular}

Note: There are total of 10 regressions to run if we included two centrality measures (out of five) in each regression. The reported results are for the centrality that appears statistically significant most frequently. For GGKT, intercentarlity and bonacich centralities appear statistically significant most frequently (3 out of 4 times). For GMT, intercentrality appears statistically significant most frequently. All regressions control for individual characteristics and school fixed effects. Standard errors are clustered at the school level. * $\mathrm{p}<0.10$; ${ }^{* *} \mathrm{p}<0.05$; *** $\mathrm{p}<0.01$ 
Table 6: Effects of own centrality on IPOMT

when two measures are included

\begin{tabular}{|c|c|c|c|c|}
\hline & (1) & (2) & (3) & (4) \\
\hline \multicolumn{5}{|c|}{ Outcome: IPOMT (N=3406) } \\
\hline \multicolumn{5}{|c|}{ Own centrality based on } \\
\hline Intercentrality & $\begin{array}{l}-0.000 \\
(0.002)\end{array}$ & & & \\
\hline Bonacich & $\begin{array}{l}0.085 \\
(0.022)^{* * *}\end{array}$ & $\begin{array}{l}0.085 \\
(0.006) * * *\end{array}$ & $\begin{array}{l}0.104 \\
(0.011)^{* * *}\end{array}$ & $\begin{array}{l}0.059 \\
(0.015)^{* * *}\end{array}$ \\
\hline Closeness & & $\begin{array}{l}0.132 \\
(0.309)\end{array}$ & & \\
\hline Eigenvector & & & $\begin{array}{l}-1.774 \\
(0.863)^{* *}\end{array}$ & \\
\hline Degree & & & & $\begin{array}{l}0.851 \\
(0.444)^{*}\end{array}$ \\
\hline \multicolumn{5}{|c|}{ Outcome: IPOMT (N=3406) } \\
\hline \multicolumn{5}{|c|}{ Own centrality based on } \\
\hline Intercentrality & $\begin{array}{l}0.005 \\
(0.001)^{* * *}\end{array}$ & & & \\
\hline Bonacich & & $\begin{array}{l}0.059 \\
(0.015)^{* * *}\end{array}$ & & \\
\hline Closeness & & & $\begin{array}{l}0.232 \\
(0.303)\end{array}$ & \\
\hline Eigenvector & & & & $\begin{array}{l}-0.570 \\
(0.940)\end{array}$ \\
\hline Degree & $\begin{array}{l}1.327 \\
(0.392)^{* * *}\end{array}$ & $\begin{array}{l}0.851 \\
(0.444)^{*}\end{array}$ & $\begin{array}{l}2.425 \\
(0.209) * * *\end{array}$ & $\begin{array}{l}2.609 \\
(0.329)^{* * *}\end{array}$ \\
\hline
\end{tabular}

Note: The reported results are for the centrality that appears statistically significant most frequently. All regressions control for individual characteristics and school fixed effects. Standard errors are clustered at the school level. * $\mathrm{p}<0.10$; ${ }^{* *} \mathrm{p}<0.05 ;{ }^{* * *} \mathrm{p}<0.01$ 
Table 7: Effects of deviation from the average centrality

\begin{tabular}{|c|c|c|c|c|c|c|}
\hline & $\begin{array}{c}(1) \\
\text { IPOMT }\end{array}$ & $\begin{array}{c}(2) \\
\text { IPOMT }\end{array}$ & $\begin{array}{c}(3) \\
\text { IPOMT }\end{array}$ & $\begin{array}{c}(4) \\
\text { IPOMT }\end{array}$ & $\begin{array}{c}(5) \\
\text { IPOMT }\end{array}$ & $\begin{array}{c}(6) \\
\text { IPOMT }\end{array}$ \\
\hline Dev. intercentrality & $\begin{array}{l}0.002 \\
(0.001)\end{array}$ & & & & & \\
\hline Higher than avg. intercentrality & $\begin{array}{l}0.116 \\
(0.034)^{* * *}\end{array}$ & & & & & \\
\hline Dev* Higher than avg intercet & $\begin{array}{l}0.005 \\
(0.001)^{* * *}\end{array}$ & & & & & \\
\hline Dev. Bonacich & & $\begin{array}{l}-0.004 \\
(0.012)\end{array}$ & & & & \\
\hline Higher than avg. Bonacich & & $\begin{array}{l}0.042 \\
(0.040)\end{array}$ & & & & \\
\hline Dev*Higher than avg. Bonacich & & $\begin{array}{l}0.075 \\
(0.014)^{* * *}\end{array}$ & & & & \\
\hline Dev. Closeness & & & $\begin{array}{l}0.250 \\
(0.443)\end{array}$ & & & \\
\hline Higher than avg. Closeness & & & $\begin{array}{l}0.105 \\
(0.035)^{* * *}\end{array}$ & & & \\
\hline Dev*Higher than avg. Closeness & & & $\begin{array}{l}-0.015 \\
(0.474)\end{array}$ & & & \\
\hline Dev. Betweeness & & & & $\begin{array}{l}-0.487 \\
(0.647)\end{array}$ & & \\
\hline Higher than avg. Betweeness & & & & $\begin{array}{l}0.052 \\
(0.041)\end{array}$ & & \\
\hline Dev*Higher than avg. Betweeness & & & & $\begin{array}{l}0.174 \\
(0.682)\end{array}$ & & \\
\hline Dev. Eigenvector & & & & & $\begin{array}{l}0.544 \\
(0.843)\end{array}$ & \\
\hline Higher than avg. Eigenvector & & & & & $\begin{array}{l}0.103 \\
(0.042)^{* *}\end{array}$ & \\
\hline Dev*Higher than avg. Eigenvector & & & & & $\begin{array}{l}2.790 \\
(1.284)^{* *}\end{array}$ & \\
\hline Dev. Degree & & & & & & $\begin{array}{l}0.278 \\
(0.315)\end{array}$ \\
\hline Higher than avg. Degree & & & & & & $\begin{array}{l}0.087 \\
(0.035)^{* *}\end{array}$ \\
\hline Dev*Higher than avg. Degree & & & & & & $\begin{array}{l}1.741 \\
(0.403)^{* * *}\end{array}$ \\
\hline
\end{tabular}

Note: Each column shows the results from each different regression. All regressions control for individual characteristics and school fixed effects. Standard errors are clustered at the school level. * $\mathrm{p}<0.10 ;{ }^{* *} \mathrm{p}<0.05 ; * * * \mathrm{p}<0.01$ 
Table 8: Effects of maximum and minimum centrality on group outcomes

\begin{tabular}{lcc}
\hline & $(1)$ & $(2)$ \\
& GGKT & GMT \\
\hline Intercentrality & 0.003 & 0.004 \\
Bonacich & $(0.001)^{* * *}$ & $(0.001)^{* * *}$ \\
& 0.041 & 0.044 \\
Closeness & $(0.010)^{* * *}$ & $(0.011)^{* * *}$ \\
& 1.044 & 1.430 \\
Betweenness & $(0.459)^{* *}$ & $(0.480)^{* * *}$ \\
& -0.677 & -0.842 \\
Eigenvector & $(0.470)$ & $(0.509)$ \\
& 1.756 & 2.555 \\
Degree & $(0.675)^{* *}$ & $(0.701)^{* * *}$ \\
& 0.742 & 1.098 \\
Panel B -Minimum centrality in the group based & $(0.305)^{* *}$ & $(0.342)^{* * *}$ \\
Intercentrality & -0.000 & \\
& $(0.006)$ & 0.005 \\
Bonacich & -0.003 & $(0.008)$ \\
Closeness & $(0.033)$ & 0.032 \\
Betweenness & 1.243 & $(0.040)$ \\
Eigenvector & $(0.834)$ & 0.216 \\
Degree & 3.541 & $(0.702)$ \\
& $(1.924)^{*}$ & 0.245 \\
& 1.732 & $(1.853)$ \\
& $(3.342)$ & $(3.199$ \\
& -0.328 & 1.139 \\
& $(0.913)$ & $(0.992)$ \\
& & \\
& & \\
& &
\end{tabular}

Note: Each coefficient on centrality is obtained from each different regression.

All regressions control for individual (or group in group outcomes) characteristics and school fixed effects. Leader (panel A) or weakest link (panel B)'s math baseline test, IPEMT, according to each centrality measure is also controlled in the regression.

Standard errors are clustered at the school level. ${ }^{*} \mathrm{p}<0.10$; ${ }^{* *} \mathrm{p}<0.05$; ${ }^{* * *} \mathrm{p}<0.01$ 
Table 9: Effects of maximum of centrality when two measures are included (Group outcomes)

$(1)$

(2)

(3)

(4)

\section{Outcome: GGKT (N=924)}

Max centrality in the group based on

Intercentrality

$-0.004$

(0.004)

Bonacich

$$
0.081
$$

$(0.043)^{*}$

Closeness

Eigenvector

0.040
$(0.010)^{* * *}$
0.035
$(0.596)$

0.052

0.063

$(0.015)^{* * *}$

$(0.019)^{* * *}$

(0.596)

$-0.880$

(0.833)
Degree

$-0.797$

$(0.476)^{*}$

Outcome: GMT (N=924)

Intercentrality

0.002

0.004

$(0.001)^{* * *}$

0.003

0.003

(0.004)

0.017

(0.053)

Closeness

0.518

(1.060)

Eigenvector

1.083

(1.068)

Degree

0.130

(0.650)

Outcome: GMT (N=924)

Intercentrality

0.002

(0.004)

Bonacich

0.017

0.043

0.031

0.040

(0.053)

$(0.011)^{* * *}$

$(0.018)^{*}$

$(0.024)^{*}$

Closeness

0.504

(1.058)

Eigenvector

0.975

(1.105)

Degree

0.066

(0.676)

Note: For each outcome, the reported results are for the centrality that appears statistically significant most frequently. For GGKT, bonacich centrality appears statistically significant most frequently, followed by intercentrality (3 out of 4 times). All regressions control for individual characteristics and school fixed effects. Standard errors are clustered at the school level. ${ }^{*} \mathrm{p}<0.10 ;{ }^{* *} \mathrm{p}<0.05 ;{ }^{* * *}$ $\mathrm{p}<0.01$ 
Table 10: Effects of maximum of centrality on individual outcomes

\begin{tabular}{|c|c|c|c|}
\hline & $\begin{array}{c}(1) \\
\text { IPOMT }\end{array}$ & $\begin{array}{c}(2) \\
\text { IPOMT }\end{array}$ & $\begin{array}{c}(3) \\
\text { IPOMT }\end{array}$ \\
\hline Max Intercentrality & $\begin{array}{c}0.003 \\
(0.001)^{* * *}\end{array}$ & $\begin{array}{c}0.000 \\
(0.001)\end{array}$ & $\begin{array}{c}0.001 \\
(0.001)^{*}\end{array}$ \\
\hline Own Intercentrality & & $\begin{array}{c}0.008 \\
(0.001)^{* * *}\end{array}$ & $\begin{array}{c}0.012 \\
(0.001)^{* * *}\end{array}$ \\
\hline Max Intercentrality * Own Intercentrality & & & $\begin{array}{c}-0.000 \\
(0.000)^{* * *}\end{array}$ \\
\hline Max Bonacich & $\begin{array}{c}0.033 \\
(0.005)^{* * *}\end{array}$ & $\begin{array}{c}0.005 \\
(0.006)\end{array}$ & $\begin{array}{c}0.009 \\
(0.006)\end{array}$ \\
\hline Own Bonacich & & $\begin{array}{c}0.074 \\
(0.007)^{* * *}\end{array}$ & $\begin{array}{c}0.085 \\
(0.017)^{* * *}\end{array}$ \\
\hline Max Bonacich * Own Bonacich & & & $\begin{array}{l}-0.001 \\
(0.002)\end{array}$ \\
\hline Max Closeness & $\begin{array}{c}0.089 \\
(0.255)\end{array}$ & $\begin{array}{c}0.174 \\
(0.244)\end{array}$ & $\begin{array}{c}1.105 \\
(1.348)\end{array}$ \\
\hline Own Closeness & & $\begin{array}{c}1.735 \\
(0.295)^{* * *}\end{array}$ & $\begin{array}{c}2.747 \\
(1.449)^{*}\end{array}$ \\
\hline Max Closeness * Own Closeness & & & $\begin{array}{l}-1.685 \\
(2.259)\end{array}$ \\
\hline Max Betweenness & $\begin{array}{c}0.103 \\
(0.321)\end{array}$ & $\begin{array}{l}-0.058 \\
(0.345)\end{array}$ & $\begin{array}{c}0.128 \\
(0.353)\end{array}$ \\
\hline Own Betweenness & & $\begin{array}{c}0.415 \\
(0.339)\end{array}$ & $\begin{array}{c}1.168 \\
(0.742)\end{array}$ \\
\hline Max Betweenness * Own Betweenness & & & $\begin{array}{l}-4.463 \\
(3.609)\end{array}$ \\
\hline Max Eigenvector & $\begin{array}{c}1.541 \\
(0.457)^{* * *}\end{array}$ & $\begin{array}{c}0.147 \\
(0.391)\end{array}$ & $\begin{array}{c}0.533 \\
(0.350)\end{array}$ \\
\hline Own Eigenvector & & $\begin{array}{c}4.177 \\
(0.730)^{* * *}\end{array}$ & $\begin{array}{c}6.610 \\
(0.882)^{* * *}\end{array}$ \\
\hline Max Eigenvector * Own Eigenvector & & & $\begin{array}{c}-16.936 \\
(3.473)^{* * *}\end{array}$ \\
\hline Max Degree & $\begin{array}{c}0.891 \\
(0.175)^{* * *}\end{array}$ & $\begin{array}{c}0.118 \\
(0.172)\end{array}$ & $\begin{array}{c}0.368 \\
(0.175)^{* *}\end{array}$ \\
\hline Own Degree & & $\begin{array}{c}2.114 \\
(0.230)^{* * *}\end{array}$ & $\begin{array}{c}3.175 \\
(0.438)^{* * *}\end{array}$ \\
\hline Max Degree * Own Degree & & & $\begin{array}{c}-3.389 \\
(1.075)^{* * *}\end{array}$ \\
\hline
\end{tabular}

Note: All regressions control for individual characteristics, leader (according to each centrality measure)'s math baseline test, and school fixed effects. Leader's baseline math test was never statistically significant and the results are omitted. Standard errors are clustered at the school level.

${ }^{*} \mathrm{p}<0.10$; ** $\mathrm{p}<0.05 ;{ }^{* * *} \mathrm{p}<0.01$ 
Table 11: Effects of minimum of centrality on individual outcomes

\begin{tabular}{|c|c|c|c|}
\hline & $\begin{array}{l}(1) \\
\text { IPOMT }\end{array}$ & $\begin{array}{l}(2) \\
\text { IPOMT }\end{array}$ & $\begin{array}{c}(3) \\
\text { IPOMT }\end{array}$ \\
\hline Min Intercentrality & $\begin{array}{c}0.005 \\
(0.003)^{*}\end{array}$ & $\begin{array}{c}0.002 \\
(0.003)\end{array}$ & $\begin{array}{c}0.002 \\
(0.003)\end{array}$ \\
\hline Own Intercentrality & & $\begin{array}{l}0.008 \\
(0.001)^{* * *}\end{array}$ & $\begin{array}{l}0.008 \\
(0.001)^{* * *}\end{array}$ \\
\hline Min Intercentrality * Own Intercentrality & & & $\begin{array}{l}-0.000 \\
(0.000)\end{array}$ \\
\hline Min Bonacich & $\begin{array}{l}0.032 \\
(0.016)^{* *}\end{array}$ & $\begin{array}{c}0.007 \\
(0.016)\end{array}$ & $\begin{array}{c}0.007 \\
(0.029)\end{array}$ \\
\hline Own Bonacich & & $\begin{array}{l}0.076 \\
(0.006)^{* * *}\end{array}$ & $\begin{array}{l}0.077 \\
(0.012)^{* * *}\end{array}$ \\
\hline Min Bonacich * Own Bonacich & & & $\begin{array}{l}-0.001 \\
(0.002)\end{array}$ \\
\hline Min Closeness & $\begin{array}{l}-0.049 \\
(0.359)\end{array}$ & $\begin{array}{c}0.072 \\
(0.369)\end{array}$ & $\begin{array}{l}1.525 \\
(1.546)\end{array}$ \\
\hline Own Closeness & & $\begin{array}{c}1.733 \\
(0.290)^{* * *}\end{array}$ & $\begin{array}{c}3.092 \\
(1.411)^{* *}\end{array}$ \\
\hline Min Closeness * Own Closeness & & & $\begin{array}{l}-2.635 \\
(2.672)\end{array}$ \\
\hline Min Betweenness & $\begin{array}{l}-0.476 \\
(1.127)\end{array}$ & $\begin{array}{l}-0.582 \\
(1.135)\end{array}$ & $\begin{array}{l}-1.601 \\
(1.422)\end{array}$ \\
\hline Own Betweenness & & $\begin{array}{c}0.399 \\
(0.321)\end{array}$ & $\begin{array}{c}0.177 \\
(0.364)\end{array}$ \\
\hline Min Betweenness * Own Betweenness & & & $\begin{array}{c}17.612 \\
(12.379)\end{array}$ \\
\hline Min Eigenvector & $\begin{array}{c}1.281 \\
(0.830)\end{array}$ & $\begin{array}{c}0.716 \\
(0.856)\end{array}$ & $\begin{array}{c}0.345 \\
(0.845)\end{array}$ \\
\hline Own Eigenvector & & $\begin{array}{l}4.264 \\
(0.740)^{* * *}\end{array}$ & $\begin{array}{l}4.182 \\
(0.781)^{* * *}\end{array}$ \\
\hline Min Eigenvector * Own Eigenvector & & & $\begin{array}{c}23.311 \\
(36.655)\end{array}$ \\
\hline Min Degree & $\begin{array}{c}0.763 \\
(0.389)^{*}\end{array}$ & $\begin{array}{c}0.156 \\
(0.406)\end{array}$ & $\begin{array}{c}0.258 \\
(0.475)\end{array}$ \\
\hline Own Degree & & $\begin{array}{l}2.171 \\
(0.220)^{* * *}\end{array}$ & $\begin{array}{l}2.198 \\
(0.273)^{* * *}\end{array}$ \\
\hline Min Degree * Own Degree & & & $\begin{array}{l}-0.973 \\
(3.991)\end{array}$ \\
\hline
\end{tabular}

Note: All regressions control for individual characteristics, weakest link (according to each centrality measure)'s math baseline test, and school fixed effects. Weakest link's baseline math test was never statistically significant and the results are omitted. Standard errors are clustered at the school level. * $\mathrm{p}<0.10$;** $\mathrm{p}<0.05 ; * * * \quad \mathrm{p}<0.01$ 
Table 12: Centrality, Cognitive and Non-Cognitive Outcomes

\begin{tabular}{|c|c|c|c|c|c|c|}
\hline & (1) & (2) & (3) & (4) & (5) & (6) \\
\hline & \multicolumn{3}{|c|}{ Intercentrality } & \multicolumn{3}{|c|}{ Katz-Bonacich } \\
\hline \multirow[t]{2}{*}{ IPEMT } & 0.251 & 0.181 & 0.204 & 0.0139 & 0.00486 & 0.0114 \\
\hline & $(0.294)$ & $(0.292)$ & $(0.294)$ & $(0.0370)$ & $(0.0367)$ & $(0.0366)$ \\
\hline \multirow[t]{2}{*}{ Risk-taking } & & -0.396 & -1.579 & & -0.0593 & -0.239 \\
\hline & & (3.117) & (3.100) & & $(0.391)$ & $(0.386)$ \\
\hline \multirow[t]{2}{*}{ Time preference } & & $3.210^{*}$ & $3.261^{*}$ & & $0.465 * *$ & $0.461 * *$ \\
\hline & & (1.749) & (1.739) & & $(0.220)$ & $(0.216)$ \\
\hline \multirow[t]{2}{*}{ Competetition } & & $15.98 * * *$ & $15.13^{* * *}$ & & $2.078 * * *$ & $1.977 * * *$ \\
\hline & & $(5.036)$ & $(5.045)$ & & $(0.632)$ & $(0.628)$ \\
\hline \multirow[t]{2}{*}{ Controls } & No & No & Yes & No & No & Yes \\
\hline & & Closeness & & & Betweenness & \\
\hline \multirow[t]{2}{*}{ IPEMT } & 0.0015 & 0.000920 & 0.000851 & -0.00109 & -0.00123 & -0.00120 \\
\hline & (0.00113) & (0.00107) & $(0.00109)$ & $(0.000842)$ & $(0.000842)$ & $(0.000855)$ \\
\hline \multirow[t]{2}{*}{ Risk-taking } & & $0.0393 * * *$ & $0.0373 * * *$ & & 0.00253 & 0.00181 \\
\hline & & $(0.0114)$ & $(0.0115)$ & & $(0.00898)$ & $(0.00901)$ \\
\hline \multirow[t]{2}{*}{ Time preference } & & 0.00425 & 0.00468 & & 0.00639 & 0.00539 \\
\hline & & $(0.00642)$ & $(0.00645)$ & & $(0.00504)$ & $(0.00505)$ \\
\hline \multirow[t]{2}{*}{ Competetition } & & $0.135 * * *$ & $0.131 * * *$ & & $0.0324 * *$ & $0.0312 * *$ \\
\hline & & $(0.0185)$ & $(0.0187)$ & & $(0.0145)$ & $(0.0147)$ \\
\hline \multirow[t]{2}{*}{ Controls } & No & No & Yes & No & No & Yes \\
\hline & & Eigenvector & & & Degree & \\
\hline \multirow[t]{2}{*}{ IPEMT } & 0.000508 & 0.000281 & 0.000379 & 0.00193 & 0.00142 & 0.00124 \\
\hline & $(0.000502)$ & $(0.000486)$ & $(0.000474)$ & $(0.00139)$ & $(0.00136)$ & (0.00138) \\
\hline \multirow[t]{2}{*}{ Risk-taking } & & $0.0118 * *$ & $0.00853 *$ & & 0.0145 & 0.00946 \\
\hline & & (0.00519) & $(0.00500)$ & & $(0.0145)$ & $(0.0145)$ \\
\hline \multirow[t]{2}{*}{ Time preference } & & 0.00223 & 0.00261 & & 0.0102 & 0.0104 \\
\hline & & (0.00291) & $(0.00280)$ & & $(0.00814)$ & $(0.00813)$ \\
\hline \multirow[t]{2}{*}{ Competetition } & & $0.0494 * * *$ & $0.0463 * * *$ & & $0.112 * * *$ & $0.106^{* * *}$ \\
\hline & & $(0.00838)$ & $(0.00813)$ & & $(0.0234)$ & $(0.0236)$ \\
\hline Controls & No & No & Yes & No & No & Yes \\
\hline
\end{tabular}

Notes: The games were played among all students in 16 out of 80 randomly selected schools. Ability (Cognitive ability) is measured by the standardized math test score at the baseline (before grouping). Risk-taking=1 if the students choose to draw the highest number of pencils. Wait=1 if student choose to get 3 candies two days later as opposed to two candies tomorrow. Compete $=1$ if the student choose to compete the number game with an anonymous classmate. Controls include student and household characteristics such as sex of the student, per-capita household income, parents' education and age, whether household has electricity.

$\mathrm{N}=512$. Standard errors are clustered at the school level. * $\mathrm{p}<0.10$; ${ }^{* *} \mathrm{p}<0.05 ;{ }^{* * *} \mathrm{p}<0.01$ 